\title{
FAMILY COPING AND ADAPTATION AMONG \\ GRANDPARENTS REARING GRANDCHILDREN
}

by

Fonda K Porterfield

A thesis submitted in partial fulfillment of the requirements for the degree

of

Master of Science

in

Health and Human Development

\section{MONTANA STATE UNIVERSITY \\ Bozeman, Montana}

May 2007 


\section{(C) COPYRIGHT}

$$
\text { by }
$$

Fonda K Porterfield

2007

All Rights Reserved 


\title{
APPROVAL
}

of a thesis submitted by

\author{
Fonda K Porterfield
}

This thesis has been read by each member of the thesis committee and has been found to be satisfactory regarding content, English usage, format, citations, bibliographic style, and consistency, and is ready for submission to the Division of Graduate Education.

Bethany Letiecq, Ph.D.

Approval for the Department of Health and Human Development

Craig Stewart, Ed.D.

Approval for the Division of Graduate Education

Dr. Carl A. Fox 


\section{STATEMENT OF PERMISSION TO USE}

In presenting this thesis in partial fulfillment of the requirements for a master's degree at Montana State University, I agree that the Library shall make it available to borrowers under rules of the Library.

If I have indicated my intention to copyright this thesis by including a copyright notice page, copying is allowable only for scholarly purposes, consistent with "fair use" as prescribed in the U. S. Copyright Law. Requests for permission for extended quotation from or reproduction of this thesis in whole or in parts may be granted only by the copyright holder.

Fonda K Porterfield

May, 2007 
TABLE OF CONTENTS

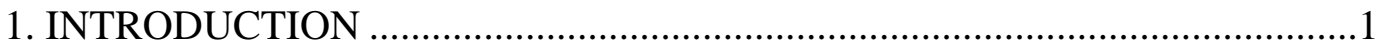

Definitions of Terms ...........................................................................4

2. REVIEW OF LITERATURE ..............................................................6

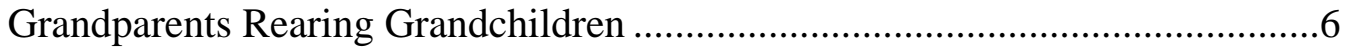

Theoretical Framework Guiding This Study .................................................8

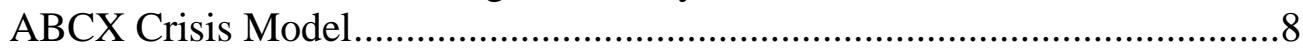

Demands (A Factor) ....................................................................... 8

Resources (B Factor)........................................................................ 9

Family's Perception (C Factor)......................................................... 10

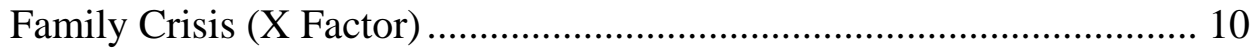

Double ABCX Model ...............................................................................11

A Contextual Model of Family Stress Theory.............................................14

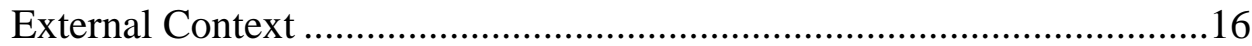

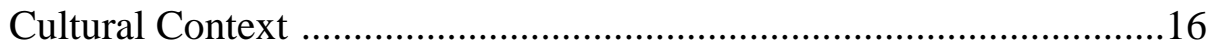

Historical Context ............................................................................17

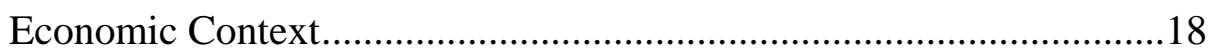

Developmental Context ................................................................19

Hereditary Context.........................................................................19

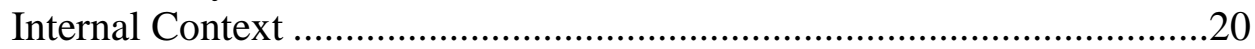

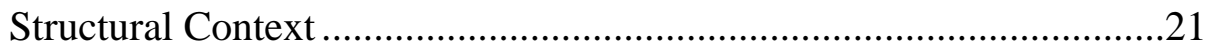

Psychological Context ............................................................22

Philosophical Context ................................................................22

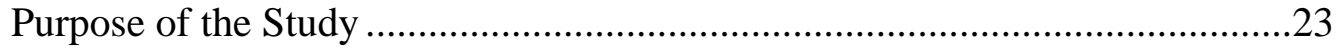

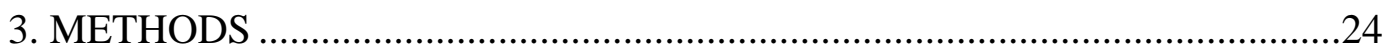

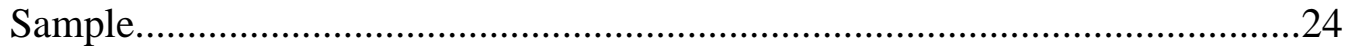

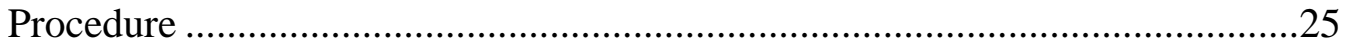

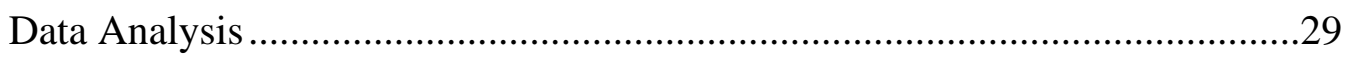




\section{TABLE OF CONTENTS - CONTINUED}

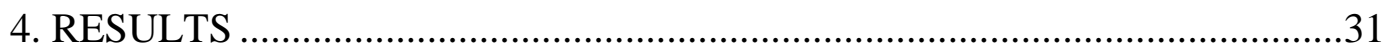

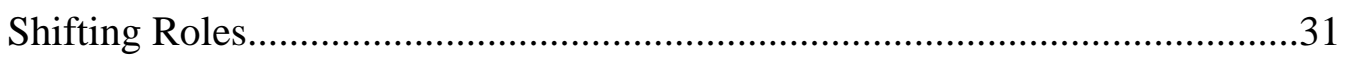

From Retirement Planning to Primary Caregiving .......................................32

Full-Time Employee to Stay-At-Home Parent .............................................34

A Second Chance to Parent..........................................................................36

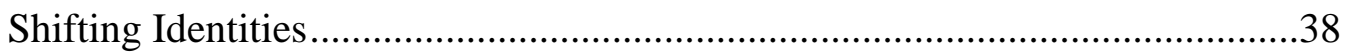

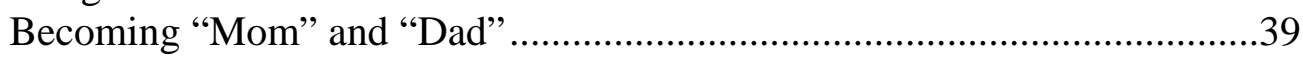

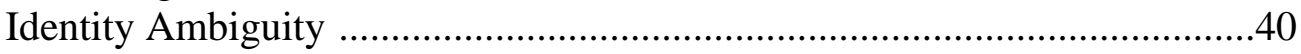

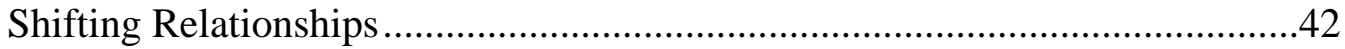

Letting Go of the Parents .........................................................................43

Shifting Family Relationships.............................................................44

Shifting Community Relationships......................................................46

Shifting Resources ..........................................................................48

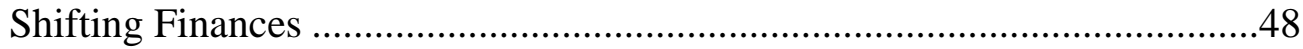

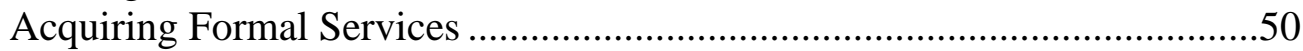

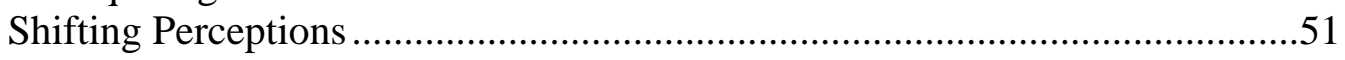

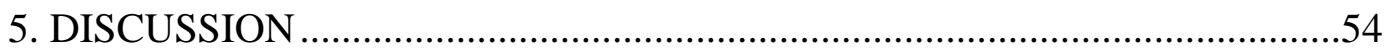

Study Limitations and Future Research .....................................................59

Implications for Practitioners and Policymakers .........................................61

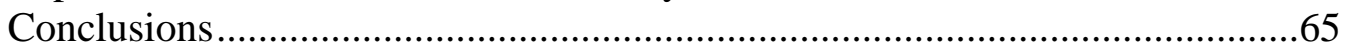

REFERENCES CITED.....................................................................67

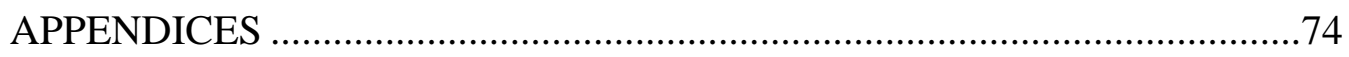

APPENDIX A: Grandparents Raising Grandchildren: Family Life Histories Interview Protocol.............................................................................75

APPENDIX B: Family Life Histories of Rural Grandparent Caregivers

Consent Form ..................................................................................81

APPENDIX C: Grandparents Raising Grandchildren: Family Life Histories

Participant Information Sheet ..............................................................84

APPENDIX D: Human Subjects Approval ...............................................87

APPENDIX E: Human Subjects Education Certificate..............................89 


\section{LIST OF FIGURES}

Figure

Page

1. Range of Out Comes in Family Functioning ...................................................

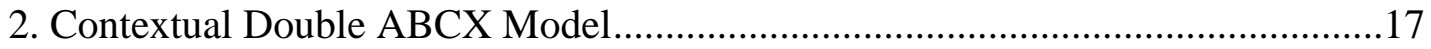




\begin{abstract}
Over the past decade, grandparent caregiving, in which grandparents take on the sole custody of their grandchildren without a parent present, has been one of the fastest growing family forms in the U.S. Most studies on grandparent caregiver functioning have focused on the challenges and deficits of grandfamilies. Little research has been conducted on the adaptive processes of grandparent caregivers and the coping mechanisms they employ to deal with parenting the second time around.

The current study was based on qualitative data generated from 26 in-depth, faceto-face interviews with grandparents who were rearing their grandchildren. Interviews were conducted with 10 grandfathers and 23 grandmothers who were the sole care providers of their grandchildren. The majority of grandparents were providing care for their grandchildren due to their adult child's substance abuse and/or mental illness. During each interview, a semi-structured interview protocol was followed. These interviews began by generating a genogram of the family system, including four generations of the family: the grandparents' parents, the grandparents, their adult children, and their grandchildren. This study was guided by McCubbin and Patterson's Double ABCX Model as well as Boss’ Family Stress Model, which situates custodial grandparents within external and internal contexts. The study explored the following research questions: What are the adaptation processes used by grandfamilies? And what coping strategies and resources do custodial grandparents employ to ameliorate their familial stressors?

The goal of this study was to explore grandparents' key processes that facilitate successful family adaptation and resilience. Findings revealed that grandparents in this study made at least five salient shifts in their family functioning. Caregivers shifted their identities; their roles; their relationships with family, friends, and communities; their resources (e.g., social supports, government assistance); and their perceptions in order to best meet the needs of their grandchildren. The grandfamilies' adaptation processes were influenced by both external and internal contexts. Understanding custodial grandparents' resilient pathways may hold important implications for future programs and policies intended to better support these families.
\end{abstract}




\section{CHAPTER 1}

\section{INTRODUCTION}

Grandparent-headed households are the fastest growing household type in the United States (Bullock, 2004). From 1990 to 1998, “skipped generation” households, in which neither member of the parent generation was present, increased by 52 percent (Fuller-Thomson \& Minkler, 2003). This phenomenon has been found to cut across all races and socio-economic statuses; however, in Montana and other rural states, this family constellation is growing at an exceptionally rapid pace. In fact, of the top ten states reporting an increase in grandparent-headed households, only one (Minnesota) was not a western state (U.S. Census, 2000).

There are several reasons grandparents are called upon to raise their grandchildren including: child abuse and neglect, parental drug abuse, teen pregnancy, divorce, single parent households, incarceration, disability, mental illnesses, physical illness, and parental death (Bowers \& Myers, 1999; Casper \& Bryson, 1998; Emick \& Hayslip, 1999; Fuller-Thomson, Minkler, \& Driver, 1997; Minkler \& Fuller-Thomson, 2000). These factors are not, however, mutually exclusive; one risk factor can exacerbate others. For example, the presence of a mental illness can influence and possibly contribute to drug and alcohol dependence.

Regardless of the circumstances leading to grandchildren being reared by their grandparents, a commonality exists: the grandparents have been called upon by family or authorities to relieve a crisis situation in which the parents are unable or unwilling to care 
for their own children. Studies indicate that a sense of duty to care for their family members may be the motivation for grandparents to parent their grandchildren. Sands and Goldberg-Glen (2000) found grandparents frequently reported being faced with the difficult choice of either taking over the care of the grandchildren, allowing them to remain in an unsafe situation, or allowing them to be raised in foster care. Faced with these choices, many grandparents feel a moral obligation to care for their grandchildren despite the financial, physical, and emotional hardships that doing so may bring.

During a separation from their parents, living with relatives may minimize the trauma on children by providing them with a sense of family support (Billing, Ehrle, \& Kortenkamp, 2002). Researchers have, however, found both positive and negative consequences of caregiving for the grandparents. Whitley et al. (2001) indicated that the caregiving role can have negative effects on the grandparents. The tribulations of parenting for the second time have been found to lead to psychological, social, economic, and physical distress. Despite these negative effects, grandmothers have been found to have a high sense of perseverance and determination to continue their responsibilities (Roe, Minkler, Saunders, \& Thompson, 1996).

The social support needs (Mayer, 2002), coping skills (Ross \& Aday, 2006; Musil, 1998), and resources utilized by grandparents to manage with these hardships have been the subject of many studies (Burnette, 1999; Emick \& Hayslip, 1999; Kelley, Whitley, Sipe, \& Yorker, 2000; Landry-Meyer, Gerard, \& Guzell, 2005; Musil \& Ahmad, 2002; Musil, Warner, Zauszniewski, Jeanblanc, \& Kercher, 2006; Strom \& Strom, 2000). Grandparents often must utilize all their resources and coping skills as they 
attempt to meet the demands of parenting for the second time. Most studies on grandparents' functioning have focused on the challenges faced by of grandfamilies. Little research has been conducted on the coping processes of custodial grandparents as they move from the initial crisis phase when they take in their grandchildren to the adjustment phase where they work to meet the daily needs of their families.

Guided by McCubbin and Patterson’s (1983) Double ABC-X Family Stress Theory and Boss's Family Stress Model (2004), this study examined the following research questions: What are the adaptation processes of grandparents rearing their grandchildren? And what coping strategies and resources do custodial grandparents employ to ameliorate their familial stressors and promote family resiliency? The goal of this study was to explore grandparents' key processes that facilitate successful family adaptation and resilience. Understanding custodial grandparents' adaptation pathways may hold important implications for future programs and policies intended to better support these families. 


\section{Definitions of Terms}

- Bonadaptation (also known as regenerative power) are the processes identified in McCubbin’s Double ABCX Model by which families restore balance after a family crisis. Bonadaptation is observed in the family's (a) continued ability to promote the development of individual family members and (b) willingness to maintain their family unit so it can accomplish its life cycle tasks.

- Custodial grandparent refers to those grandparents who are the primary caregivers of their grandchildren. The grandchildren reside with custodial grandparents on a full-time basis without the presence of the parents. The arrangement may be formal or informal. Formal arrangements are those in which the placement of the grandchildren with their grandparents is court mandated. Informal arrangements are those in which the arrangement has been made within the family without court intervention. These terms do not give any indication of the length of care.

- Family crisis is a result of family stress in which there is “(a) a disturbance in the equilibrium that is so overwhelming, (b) a pressure is so severe, or (c) a change that is so acute that the family system is blocked, immobilized, incapacitated” (Boss, 2004, p. 62).

- Family resilience refers to the characteristics, dimensions, and properties of families which help families to be resistant to disruption in the face of change and adaptive in the face of crisis situations (McCubbin \& McCubbin, 1988). 
- Family stress refers to the pressure or tension in the family system-a disturbance in the steady state of the family (Boss, 2002).

- Life Course refers to the socially constructed timing of events over the course of a lifespan. Events that follow the normative framework are considered to be "on time.” Events occurring out of sync with the normative framework are considered to be “off time.” (Demo, Aquilino, \& Fine, 2005).

- Maladaptation (also known as vulnerability) refers to processes families engage in leading to poor adaptation in McCubbin's Double ABCX Model (McCubbin and Patterson, 1983).

- Resilience is the family's ability to emerge strengthened and more resourceful after encountering stressor events, persistent stress, or crisis and to "withstand and rebound from disruptive life changes” (Walsh, 1998, p.3).

- Social supports are assistance provided to an individual or family that affects the functioning of that individual or family (Dunst, Trivette, \& Deal, 1988). 


\section{CHAPTER 2}

\section{REVIEW OF LITERATURE}

\section{Grandparents Rearing Grandchildren}

Researchers have confirmed that the phenomenon of grandparents rearing their grandchildren has been rising at a significant rate in the United States (Kelley et al., 2001; Fuller-Thompson, Minkler, \& Diver, 1997). The U.S. Census (2000) has documented increases in the numbers of grandparent-headed households in all states, with the exception of Washington D.C.; the states with the highest percentage increases were concentrated in the western portion of the country. Montana, where this study took place, experienced a 53.8\% increase between 1990 and 2000, ranking ninth in the country for an increase in grandparent-headed households. The U.S. Census Bureau (2003) estimated that nationally, nearly 2.5 million grandparents had sole responsibility for their grandchildren, and over 6,000 grandparents in Montana were the sole providers for their grandchildren.

In response to their growing numbers, grandfamilies have received increased attention by family researchers over the past two decades. Researchers have studied (among other things) the physical and mental health outcomes of grandparents caregivers (Kelley, Whitley, Sipe, \& Yorker, 2000; Whitley, Kelley, \& Sipe, 2001), the stress and role strain experienced by these caregivers (Bullock, 2004; Landry-Meyer \& Newman, 2004; Lever \& Wilson, 2005), and the limited resources and supports available to 
grandparents and other relatives rearing their related children (Mayer, 2002). Both grandparents and grandchildren in these situations are thought to be at risk emotionally, physically, and socially (Smith, Savage-Stevens, \& Fabian, 2002). However, while the challenges faced by custodial grandparents have been identified, extant literature is deficient regarding the processes grandparents experience as they adjust to their new roles.

In this study, family stress theory and the concept of family resilience were integrated to elucidate the key adaptation processes grandparents employ to buffer themselves and their family members from the stresses associated with taking on the role of custodial parents of their grandchildren. The examination of family processes has been shown by a growing body of systems-based research to be a more salient indicator of healthy individual and family functioning than the family form (Walsh, 1996). Understanding custodial grandparents’ adaptation processes may therefore hold important implications for future programs and policies intended to better support these families.

To explore custodial grandparents' coping and adaptation processes, this qualitative study was guided by two questions: What are the adaptation processes of grandparents who are rearing their grandchildren in the absence of biological parents? And what coping strategies and resources do custodial grandparents employ to ameliorate their familial stressors and promote family resilience? There are a number of theoretical concepts that are relevant to understanding the processes custodial grandparents utilize as they adjust to parenting for a second time. Following is a brief theoretical review. 
Theoretical Frameworks Guiding This Study

\section{$\underline{\text { ABCX Crisis Model }}$}

All families experience stress. Stress is considered normal and inevitable, for as individual family members grow and change over time, the family also changes and with any change comes disturbance or stress (Boss, 2004). Grandparents rearing their grandchildren experience an array of normative and non-normative stressors as they navigate the changes in their family system (Boss). Hill's ABCX Model of Family Stress can be used to explain variability of grandfamilies' responses to family transitionswhether such transitions are expected or unexpected—including the basic coping strategies grandfamilies use, and the basic processes involved in adaptation to stress and family crises (McCubbin \& Figley, 1983).

Demands (A Factor). The A of the ABCX Model represents the stressor or hardship on the family. McCubbin (1983) defined a stressor as a life event (e.g., death, marriage, parenthood) impacting upon the family unit which produces, or has the potential of producing, change in the family social system. The degree of stress is not only a matter of magnitude of the event, but the family's perceptions of the event (Boss, 2004). Custodial grandparents' perceptions of taking responsibility of their grandchildren may be affected by the suddenness of the change. Researchers have found that whether life events are expected or unexpected may be more important in predicting well-being than whether the events are desirable or not (Stallings, Dunham, Gatz, Baker, \& Bengston, 1997). 
Researchers have found that custodial grandmothers suffered from family strains such as arguments between parents and children and concerns about family member's alcohol and drug use or emotional problems (Musil et al., 2006). These strains highlight the need for continued community-health efforts focused on intergenerational communication and strategies for dealing with impaired family members. Strains on the family were found to affect resource acquisition and perceptions of family interactions.

Resources (B Factor). The B refers to the family's available resources: the economic, psychological, and physical assets on which the family members can draw in response to a single stressor event or an accumulation of events. Boss (2002) explained that these resources affect the family's coping strategies. From a resiliency perspective, a family's resources can be identified as protective factors. Protective factors, which may be learned, include: attribution style, response style, cognitive style, social skills, and problem-solving skills. This study will further examine the coping processes of custodial grandparents as resources for adapting to change.

Coping strategies for custodial grandparents have been addressed by several researchers in quantitative studies (Musil \& Ahmad, 2002; Musil, 1998; Ross \& Aday, 2006). In a study of stress and coping of African American custodial grandparents, Ross and Aday (2006) reported that five coping strategies were significantly correlated to lower reported stress: positive reappraisal, accepting responsibility, confrontive coping, self-control, and distancing. All of the grandparents in their study cited prayer and faith in a higher power as a resource for assisting them in caring for their grandchildren. Other 
coping resources included relying on family and friends for assistance, day care, tutoring, special education, professional counseling, and support groups. A lack of adequate support is associated with less grandparent role satisfaction and less tolerance in dealing with problem behaviors in their grandchildren (Hayslip \& Kaminski, 2005).

Family’s Perception (C Factor). The C refers to the family's perception of the stressor event, accompanying hardships, and their effects on the family (McCubbin \& Patterson, 1983). The subjective meaning the family places on the stressor reflects the family's values and previous experiences in dealing with change and meeting crisis. Depending on the outlook of the family, the stressor event may be viewed as a challenge to be met or as an uncontrollable catastrophe.

Custodial grandparent's perception regarding their situation may be characterized by ambiguous feelings. Strom and Strom (2000) explained that while grandparents may have positive feelings about caring for their family members, they may also feel negative feelings such as anger, resentment, and guilt. Grandparents may feel angry about the unexpected responsibilities placed upon them, resentment towards their adult children who have created the situation, and guilt about things that they might have done wrong as a parent. They may also have doubts about their ability to manage by themselves as a parent for a second time.

Family Crisis (X Factor). The X refers to the crisis phase of a stressor event. The $\mathrm{X}$ factor conceptualizes the family system's degree of disruption. If the family is unable to utilize existing resources, or to redefine the situation as to resist change, the situation 
may reach crisis proportions (McCubbin \& Patterson, 1983). It is very common for grandfamilies to experience crises within their families if they have excessive difficulties accessing resources suitable to their situations. Many grandparents have reported frustration with finding support through legal, health, education, and welfare systems that that seemingly set up obstacles to be overcome (Pinson-Millburn, Fabian, Schlossberg, \& Pyle, 1996).

While the ABCX Model focuses primarily on pre-crisis variables that account for differences in family coping and stress management capabilities as well as the degree of crisis in the family's outcome, it has been critiqued for not capturing the complexities of family crisis and adaptation over time. The Double ABCX Model was developed to gain a more thorough understanding of family post-crisis behavior.

\section{Double ABCX Model}

The Double ABCX Model expands on Hill's original ABCX Model by taking into account the family’s ability to overcome stresses over time. This was done by adding "post-crisis variables" in an effort to describe the accumulative life stressors and changes which may influence the family’s resilience, the new psychological and social resources families utilize in managing crisis situations, the processes families engage in to adapt to changes, and the outcome of these family efforts (McCubbin \& Patterson, 1983).

Family adaptation is the central concept in the Double ABCX Model. It is used to describe the outcomes of family efforts, thereby achieving new levels of adaptation and balance after family crisis. According to McCubbin and Patterson (1983), family 
adaptation is a result of the families achieving balance at both the individual-family level and the family-community level. Since the family is a system, family members must attend and respond to both of these levels of family functioning.

In the Double ABCX Model, the $\mathrm{xX}$ factor is represented as a continuum of adaptation to family stress with bonadaptation on the positive end of the continuum and maladaptation on the negative end of the continuum. Figure 1 shows the range of outcomes of family efforts to balance functioning. Family adaptation to manage crisis situations parallels the concept of resilience, which is a process involving complex relationships among risks, resources, and contexts (Gilgun, 1999). The concept of resilience and adaptation, while researched in family stress situations such as illnesses (Thompson, 1999) and mother-child relationships (Golby \& Bretherton, 1999), has just begun to be addressed in regards to the grandparent caregivers themselves.

According to McCubbin and Patterson (1983), two of the major factors of the Double ABCX Model are particularly relevant to family adaptation: family demands and family adaptive resources. Because the demands and needs of individuals, families, and society are dynamic, the aA factor refers to the pile-up of demands on family members. Family crises evolve and are resolved over a period of time; therefore families rarely face a single stressor. McCubbin and Patterson explained that at least five types of stressors contribute to stressor pile-up including the initial stressor, normative transitions, prior strains, the consequences of family efforts to cope, and finally, intrafamilial and social ambiguity. 


\begin{tabular}{|c|c|}
\hline MALADAPTAION & BONADAPTATION \\
\hline Deteroration in family integrity & Fa rrily integ nity strong \\
\hline Individual deve lopment curtailed & Me mber deve loprent enhanced \\
\hline Fa mily unity deve bpment curtailed & Family unit deve lopment enhanced \\
\hline Loss of fa mily independence and autonomy & $\begin{array}{r}\text { Farrily inde pendence and cortrol of } \\
\text { envinonmental influence }\end{array}$ \\
\hline \multicolumn{2}{|c|}{$\begin{array}{l}\text { Figure 1. Range of outcomes of family e fforts to balance functioning } \\
\text { (McCubbin \& Patterson, 1983, p.13) }\end{array}$} \\
\hline
\end{tabular}

The bB factor refers to family adaptive coping mechanisms and resources. These are part of the family's capabilities for meeting demands and needs which emerge from a crisis. There are three types of resources affecting family adaptation including family members’ personal resources, the family system’s internal resources, and social support.

Finally, the cC factor, which is a vital component of family functioning, refers to family definition and meaning. When a crisis demands change in a family, especially when the pile-up of demands stretches the family's resources to its limits, the only way to effectively cope is to redefine the situation so it seems manageable and valuable. Finding a new meaning in their situation aids families in clarifying the issues, hardships, and tasks so as to render them more controllable and responsive to problem-solving efforts. Redefining the situation also helps to decrease the intensity of the emotional burdens associated with the crisis situation and encourages the family unit to carry on with its fundamental tacks of promoting members’ social and emotional development. The ability of a family to form a positive appraisal of the situation as an "opportunity for growth" as 
opposed to a “devastating crisis” appears to facilitate family coping and adaptation. According to McCubbin and Patterson (1983), a positive definition which facilitates coping does not include a "Pollyanna" attitude of minimizing what is needed or a denial of the reality of the situation, both of which could hinder successful adjustment or adaptation.

Family coping in the Double ABCX Model results from the interactions between the $\mathrm{aA}, \mathrm{bB}, \mathrm{cC}$, and $\mathrm{xX}$ factors. As stated above, because the family is a social system, the family members must find balance within the family as well as within their greater community. Given the salience of a family’s context in understanding adaptation processes, Boss (2002) developed a framework that places the family stress model within two contextual frames - the external and the internal. Examining family stress, coping, and adaptation among grandfamilies within a contextual framework should help elucidate their resilience processes as they adapt.

\section{A Contextual Model of Family Stress Theory}

Boss (2002) defined family stress as "pressure or tension in the family system--a disturbance in the steady state of the family” (p.16). Family changes may originate within (e.g., births, deaths, marriage) or outside (e.g., civil rights movement, war, new technology) the family unit. During a change or stressful event, the family may have a real or perceived imbalance of resources and demands. Whether the change is perceived as positive or negative, the family members are pushed to manage their existing resources. 
If the family is unable to use existing resources or to redefine the experience to minimize change, a stressful event may escalate into crisis. A crisis is "a period of significant disequilibrium and disorganization in a family" that occurs when demands on the family outweigh their capabilities (Patterson, 2002, p.351). During crises, families are unable to restore stability and there is constant pressure to make changes in the family structure and patterns of interaction (McCubbin \& Patterson, 1993). Necessarily, crisis can be a turning point for a family, leading to major changes in structure, interaction patterns, or both.

To gain a more holistic and ecological understanding of how families adapt to changes brought about by the stressor event, it is critical to determine both the external and internal contexts of the family. McCubbin and McCubbin (1988) found that at each stage in the life cycle, family adaptation to normative transitions and stressful life events appeared to be facilitated by personal strengths of family members, family strengths, and community supports. Hence, examining family's external and internal contextual influences will allow for a better understanding of the vulnerabilities and processes of resilience utilized by custodial grandparents.

Boss's Contextual Model of Family Stress (see Figure 2) places Hill’s ABCX Model within external and internal contexts to address the other factors in addition to the stressful events that influence family vulnerability or breakdown. In this study, Boss's Contextual Model of Family Stress was integrated with McCubbin's Double ABCX Model of Family Stress to gain a better understanding of the internal and external influences on grandfamilies as they adapt to family stress or crisis over time. 
External Context. The external context is composed of dimensions which the family cannot control and includes the environment in which the family is embedded, also called the family's ecosystem. This dimension consists of the family's culture, history, economy, development, and heredity.

\section{$\underline{\text { Cultural Context }}$}

According to Boss (2002), past research has shown that the cultural context is a strong determinant of whether and how families will manage stress. The cultural context provides the canons and mores by which families define the way they live as well as the larger society's rules for coping with prejudice and stigma, problem solving, management styles, and accepted methods of managing stress.

Custodial grandparents often suffer from social stigma and guilt for having "messed up" their adult children. The myth that the grandparents are at fault for the choices of their adult children may lead judges and social workers to question the wisdom of placing children with their grandparents, wondering to what extent the grandparents are responsible for the adult child's inability to parent (de Toledo, 1999). While stigma is seen as a chronic stressor in one's environment, it is not however a prescription for defeat (Shih, 2004). 


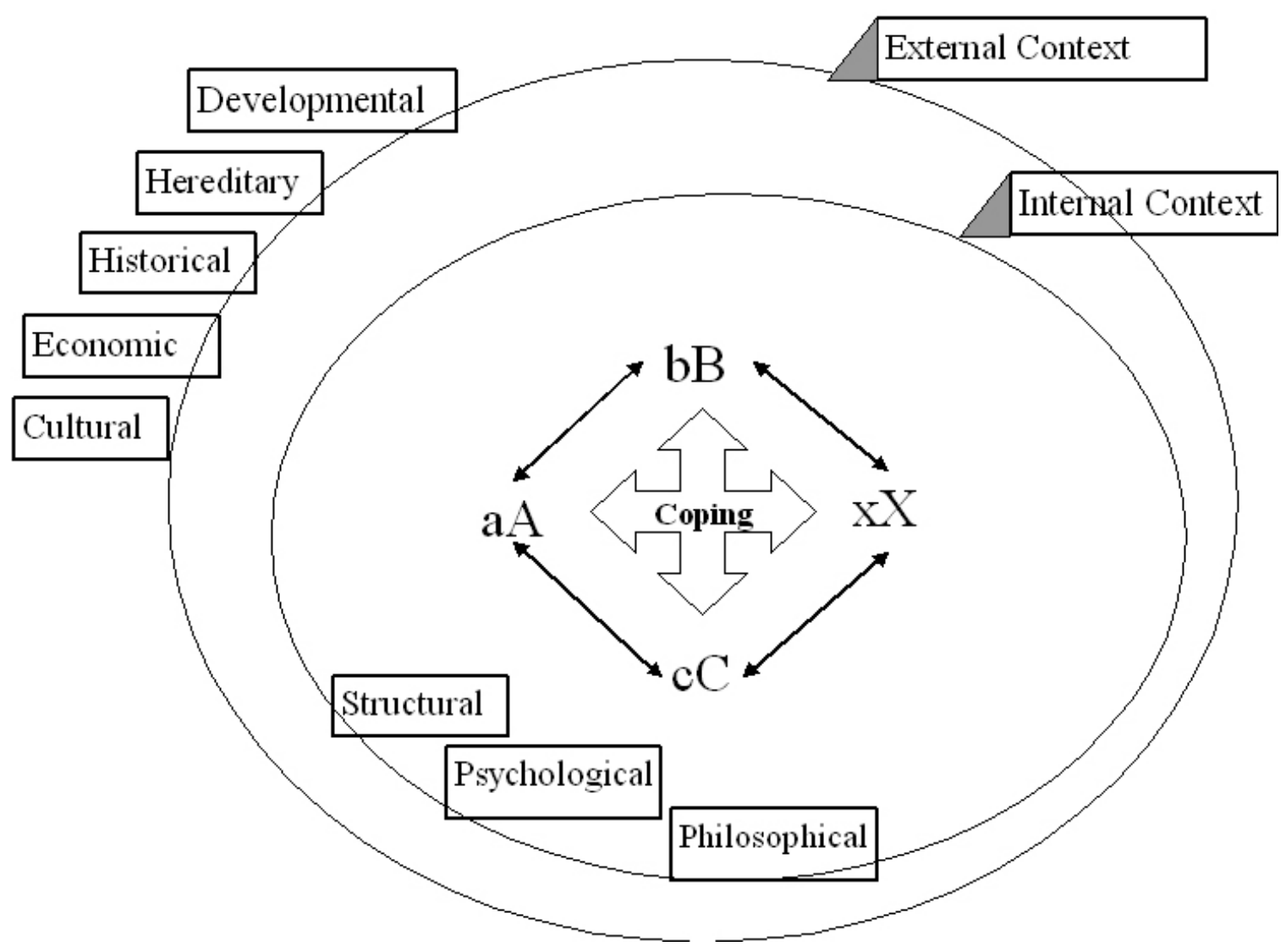

Figure 2. The Contextual Double ABCX Model

\section{$\underline{\text { Historical Context }}$}

The historical context is the time in history in which a stressor event or situation occurs that affects a family or a family member. A past event may affect the way in which a family makes meaning of situations and manages stress. For grandparents who are rearing their grandchildren, federal and state policies regarding child welfare and families that have been established affect the availability of resources for grandfamilies.

Child welfare agencies have developed a more positive attitude toward the use of family members as foster parents. Although the number of children requiring placement 
outside the home increased over the past two decades, the number of non-kin foster parents declined (Geen, 2004). Today placement with relatives is preferred with the philosophy that placement with kin is likely less traumatic for the children than placement with strangers. This recent shift in directives of child welfare agencies has lead to increases in grandfamilies across the United States.

\section{$\underline{\text { Economic Context }}$}

The economic context is the community's or society's economy which influences how the family reacts to a stressful event. The strength or weakness of the larger economy effects family’s abilities to provide for themselves or recover from financial hardships. Extant research has indicated the financial difficulties of custodial grandparents. To manage their new financial burdens some retired grandparents have returned to work, others quit their jobs because of a lack of adequate childcare, others sought out government assistance (Mayer, 2002). Waldrop and Weber (2001) explained while custodial grandparents may have a dual-income household, they may still be burdened by the extra expenses for the care of a child on an income that has already been stretched. Economic challenges may be especially daunting for grandfamilies residing in rural locales where there may be fewer opportunities to participate in social networks (Kelly et al., 2000). 


\section{Developmental Context}

The developmental context is the stage in the lifecycle of both the family unit and the individual family members in which the stressful event occurs. A family having children later in the life cycle would perceive the change differently than a family in their early years. Thus, the developmental context of the family mediates the perception of an event as much as does the event (Boss, 2002).

The age range of custodial grandparents can vary widely; they may either be in the life cycle stages of middle adulthood or late middle adulthood (Lever \& Wilson, 2005). Custodial grandparents may therefore lose the ability to accomplish many of the tasks associated with their developmental stage. Lever and Wilson concluded that grandparents may have difficulty accepting the choices that led to failure as they struggle with how they may have failed as a parent, accepting that retirement must be delayed as they parent again, and accepting the limitations as they serve as a safety net for their grandchildren from formal foster care. The developmental stage of the grandchildren may also affect the stress experienced by custodial grandparents. In a large study by FullerThomson et al. (1997), nearly half of the grandparents took in their grandchildren when the grandchildren were still infants. Caring for the immediate needs of an infant can mean purchasing many new supplies, thereby incurring substantial costs.

\section{$\underline{\text { Hereditary Context }}$}

The hereditary context of the family refers to the genetic factors that have influence over the family members, their situations, and their decisions. These factors can 
affect the physical and mental health of the family members. The genetic makeup of people can influence their abilities to manage resources and adapt to stressors.

Grandparents may find that the psychological and physical health traits in their families' history may have influence over their coping skills. The presence of genetic physical and mental illnesses may impede the abilities of some family members to cope with family stress and crisis. Researchers have found declines in physical health of grandparents after taking primary responsibilities of their grandchildren. Whitley et al. (2001) found that 45 percent of the grandmothers in their sample rated their physical health as only fair or poor. In a report by the Mathmatica Policy Research, Inc. (2002), researchers found that, although their average age was 52, non-parent caretakers that receive TANF Child-only payments have the over-all physical health similar to that of a typical 70-year-old. Regardless of obvious declines in health, custodial grandparents may downplay them to appear up to the task (Pinson-Milburn, Fabian, Schlossberg, \& Pyle, 1996). In contrast, some grandparents have claimed that their grandchildren keep them young. The results from a study by Waldrop and Weber (2001) indicated that grandparents reported becoming healthier after assuming the caregiving role, which was attributed to the increased activity.

Internal Context. The internal context of the family system is more salient for coping and stress management because it is composed of dimensions over which the family members may be capable of controlling. Boss (2002) explained that the internal context consists of structural, psychological, and philosophical dimensions which can be 
influenced by the external context. Families may try to change or improve the external causes of their situation; however, much of the time the only option is to make an internal shift in their perception of the event. Maintaining control over these internal dimensions allows the family some choices about how and whether to change.

\section{$\underline{\text { Structural Context }}$}

The structural context refers to the form and function of the family. Included are boundaries, role assignments, and rules regarding who is within and who is outside these boundaries. Boundary ambiguity can result in a lack of clarity in the structural context of the family and in the occurrence of stress. According to Mayer (2002), one central issue apt to require immediate attention when grandparents take in their grandchildren is the definition, or redefinition of family boundaries, as grandparent-headed families are founded and the grandparents take on many new tasks and responsibilities. Family boundaries may become blurred as the grandchild bonds with her grandparents and possibly coins for them a new term of endearment (Lever \& Wilson, 2005). The new structure of the grandfamily may be difficult for both the grandparents and the grandchild. The child may be angry, distrustful, and confused when their parents can no longer care for them. The grandparents may cope with grief over the circumstances that left their adult child unable to care for the grandchild as well as cope with the grandchild’s adjustment to losing their parents (Lever \& Wilson, 2005). 


\section{$\underline{\text { Psychological Context }}$}

The psychological context refers to the assessment or perception of a stressor event. The family’s perception of the event essentially determines their ability to mobilize defense mechanisms when that event occurs. Grandparents have reported increased anxiety and depression since assuming primary parenting roles of their grandchildren. Musil and Ahmad (2002) found that grandparent caregivers reported significantly worse health than non-caregiving grandparents. Psychological stress often manifests itself in various physical symptoms such as headaches, fatigue, and increased blood pressure (Whitley, Kelley, \& Sipe, 2001). It therefore seems worthy of examination to include physical health as well as psychological health to the dimensions of internal contexts influencing family resilience in grandfamilies.

\section{Philosophical Context}

Lastly, the philosophical context of family stress and adaptation refers to the values and beliefs within the family. The values of a family may differ from those of the larger society in which the family lives. The families' values and beliefs influence their strategies in regards to childrearing practices, gender roles, and care for aging relatives. If the values of the individual family differ from the policies of the government, social supports needed to maintain their families within their moral framework may be lacking. Custodial grandparents may feel that their grandchildren could be best benefited by staying within their families; however, the philosophies of child welfare workers, Guardian Ad Litems, and judges may not agree. If professionals working with families 
believe that the "apple does not fall far from the tree," children may be put into the home of a non-kin foster family in lieu of placing the children with their grandparents. The fear of losing their grandchildren to the child welfare system prevents many grandparents from pursuing formal guardianship, foster care training, or other types of governmental assistance.

The factors and mitigating influences on the grandfamilies' adaptive processes are inextricably intertwined between the internal and external contexts of family stress. The interaction of these factors may aid or inhibit the abilities of the grandfamilies to respond to their family's needs and make the necessary adaptations within their families.

\section{Purpose of the Study}

Guided by McCubbin and Patterson’s (1983) Double ABC-X Family Stress Theory and Boss’s Family Stress Model (2002), this qualitative research effort analyzed data derived from 26 family life history interviews with grandparents rearing their grandchildren without a biological parent present. This study explored the following research questions: What are the adaptation processes of grandparent caregivers? And what coping strategies and resources do custodial grandparents employ to ameliorate their familial stressors and promote family resilience? The goal of this study was to explore grandparents’ key processes that facilitate successful family adaptation and resilience. Understanding custodial grandparents’ pathways of adaptation may hold important implications for future programs and policies intended to better support these families. 


\section{CHAPTER 3}

\section{METHODS}

\section{$\underline{\text { Sample }}$}

This study used data collected for a larger study of grandfamily functioning. The sample consisted of 26 grandfamilies. Within those grandfamilies, interviews were conducted with 10 grandfathers and 23 grandmothers who were the sole care providers of their grandchildren. Grandparents ranged in age from 36 to 71 years with mean age of 56 years. Sixty-nine percent $(n=18)$ of the sample were married at the time of the interview. The remainder was single, separated, divorced, or widowed.

The family structure of grandparents raising grandchildren cut across all income levels with annual household incomes ranging from less than $\$ 15,000$ to more than $\$ 70,000$. Nearly 35\% $(n=12)$ of the households received some type of government assistance - the majority, however, reported receiving no financial assistance or services provided by the state. Education levels of grandparent caregivers were also diverse, with four participants in the sample having less than a high school diploma, nine having a high school diploma or GED, and 20 having some postsecondary education. The sample was predominantly White, with the exception of one grandparent who was Native American. In this sample, grandparents had been the primary caregivers of their grandchildren for an average of 5.5 years, with a range from four months to 24 years. Grandparents took in their grandchildren for many reasons, however 19 out of the 26 
grandfamilies' situations occurred as a result of drug and alcohol problems of the grandchildren's parents. Methamphetamines and alcohol were the most commonly reported substances. Four grandparents reported that bipolar depressive disorder was the major factor resulting in the parents not being able to care for their children; however, we could not determine in most of those cases if the disorder had been diagnosed by a clinician.

The majority of grandparents were rearing their grandchildren in "informal” or "private” arrangements. This means that the grandfamilies were not involved in the "formal" child welfare system and that the grandparents had intervened prior to state intervention and child removal. Eight of the grandfamilies were formal kin foster care providers, whereas the remainder $(n=18)$ had no involvement with the foster care system or child protective services. Of the grandparents interviewed, only four had legally adopted their grandchildren. Five were caring for their grandchildren with no legal arrangement in place. The caregiving grandparents with no legal arrangements in place had no legal rights to make medical or educational decisions on behalf of their grandchildren.

\section{Procedure}

The study was based on qualitative data generated from family life history interviews with 26 grandparents who were rearing their grandchildren. As an approach, family life history interviewing is a method whereby the researcher obtains an individual's life story, offering an opportunity for immersion into the culture and 
meaning of one’s world (Goodley, Lawthom, Clough, \& Moore, 2004). To solicit grandparent caregiver participation in the study, the research team used flyers, announcements at local support groups, and newspaper and radio advertisements. Participants were also asked to spread the word and encourage other grandparent caregivers to contact the research team to participate in the study.

Upon contact with a member of the research team, the grandparents were asked several questions to ensure they met the study's inclusion criteria. These criteria included: 1) that the grandparents were the sole care provider of their grandchild(ren); 2) that the adult child (i.e., biological parent of the child(ren) of interest) did not reside in the home with the grandparent; and 3) that the grandparent caregivers live within a 90mile radius of the university that housed the research team. Because of limited time and resources, we could not include grandfamilies that lived more than two hours driving time away from the university. Based on the inclusion criteria, there were three ineligible caregivers: one grandparent was not a full-time custodian of her grandchildren and two lived more than two hours away from the university.

Once the criteria were met, the research team member scheduled the interview at the grandparent's convenience. All interviews took place in the homes of grandparents raising their grandchildren. After obtaining grandparents’ informed consent, all participants completed a demographic form (see Appendix C) detailing information about their marital status, education level achieved, employment history, and years caregiving for grandchildren, among other characteristics. Next, the family life history interviews were conducted by two trained interviewers, who followed a semi-structured interview 
protocol (see Appendix A). These interviews were audio taped for later transcription. Only children under the age of two were present during interviews.

At the beginning of each interview, a genogram was mapped out. Each genogram included four generations of the grandparents’ families: the grandparents’ parents, the grandparents, their adult children, and their grandchildren. Genograms record information about family members and their relationships over at least three generations. Family information is displayed graphically in a way that provides a quick gestalt of complex family patterns; as such they are a rich source of hypotheses about how a clinical problem may be connected to the evolution of both the problem and the family's context over time. Each family’s genogram provided an efficient pictorial representation of the families, allowing the researchers who were unfamiliar with the families to quickly grasp a large amount of information about them and to have a view of potential problems (McGoldrick, Gerson, \& Shellenberger, 1999).

After a detailed genogram was constructed, the interviewers proceeded to probe about the circumstances surrounding the grandparents' gaining custody of their grandchildren. Next, questions turned to family relations and how the grandparents felt about their adult children and their grandchildren. Grandparents were probed with questions about familial problems and relationships with family members and their feelings about those issues. Interviews concluded with questions about resource needs and social supports used by the grandfamilies. Each interview took approximately two hours to complete. Upon completion, grandparents received \$100 for their participation and volunteer time. 
Each recorded interview was transcribed verbatim. A number was assigned to each interview to identify the case. A list of participant names and contact information was kept separate from the transcribed interviews to maintain confidentiality. The printed transcriptions were compiled in binders, along with copies of the family genograms, for coding purposes. Four members of the research team each read through the transcribed interviews. The genograms were instrumental in keeping track of all the family members and ensuring that the stories of the grandfamilies were consistent with the generational picture provided by each participant. The data were accessed by the members of the research team only. Upon completion of this study, all binders will be kept in locked file cabinets in the research team offices.

Reliability and validity were assessed using several strategies. First, a semistructured interview protocol was developed and reviewed by team members. Second, all members of the research team were trained to conduct the interviews. Two members of the team were present at each interview allowing one team member to ask questions and the other to construct the genogram, take field notes, and assure that all of the questions on the protocol were asked during each interview. To minimize bias and maximize accuracy in the findings, an "audit trail” of the data collection process was established, as suggested by Patton (2002). This audit trail is detailed below. 


\section{Data Analysis}

To explore the research questions and address study goals, four steps were used to analyze the data. First, using the inductive method of grounded theory (Glaser \& Strauss, 1967), the 26 transcribed family life history interviews were open coded. Next, the researcher identified recurrent themes that emerged in the data that reflected coping strategies, resource utilization, and adaptation processes of the grandparent caregivers. Next, a random sample of $20 \%$ of the interviews $(n=5)$ were coded by another team member to conduct a peer check. The research team then met to discuss the coding and resolve all discrepancies found in the coding. Five themes emerged at this point in the coding process. Under each theme, the researcher also identified subthemes that elucidated the themes and provided more depth of understanding. Finally, the researcher identified quotes that best represented the themes and subthemes. This step provided a richer description of the phenomena and helped establish trustworthiness of the analysis (Lincoln \& Guba, 1985).

Based on this analytical strategy, the five themes that emerged in the data each represented shifts that grandparent caregivers experienced as they moved from the initial crisis phase of taking in their grandchildren to settling down and carrying out the day-today tasks of childrearing. These adaptive themes included shifts in roles, shifts in identities, shifts in relationships, shifts in resources, and shifts in perceptions. In the Results Section, these themes or shifts (as well as emergent subthemes) are represented by quotes from the grandparents. Grandfamily pseudonyms were used throughout the 
Results Section and no identifying information was included so that all grandfamily participants would remain anonymous. 


\section{CHAPTER 4}

\section{RESULTS}

The goal of this study was to explore the pathways of adaptation among grandparents rearing grandchildren. This study was guided by two research questions: 1) what are the adaptation processes of grandparents rearing grandchildren? And 2) what coping strategies and resources do custodial grandparents utilize to ameliorate their familial stressors and promote family resilience? Based on the analyses of data, five themes emerged that highlighted the adaptive strategies used by grandparent caregivers. Those five themes included: 1) shifting roles; 2) shifting identities; 3) shifting relationships; 4) shifting resources; and 5) shifting perceptions.

\section{$\underline{\text { Shifting Roles }}$}

As noted earlier, grandparent caregivers in this study took over the surrogate parental role as a result of familial crises. All grandparents in this study reported that, at some point in their family's history, their adult children were no longer able or willing to perform their parental responsibilities. The majority of grandfamilies $(n=19)$ reported that their adult children had a substance abuse problem with methamphetamine, marijuana, or alcohol. Six grandparents reported that their adult child suffered from a mental illness, including bipolar disorder and depression. The remainder were parenting their grandchildren because of teen pregnancy $(n=5)$. 
All grandparents in this study stepped in and took over the primary care duties for their grandchildren without a biological parent present. Grandparent intervention on behalf of their grandchildren necessitated that these caregivers shift their roles and responsibilities from grandparent to parent. Three subthemes capture the role shifts experienced by most grandparents in this study, including shifting from retirement planning to primary caregiving and from "full-time employee” to "stay-at-home parent." The third subtheme that emerged, “a second chance to parent,” captured grandfathers’ shifting roles in the lives of their grandchildren.

\section{From Retirement Planning to Primary Caregiving}

Many of the grandparents in this study had at one point made the transition from parenting their biological children to planning for retirement. From a developmental perspective, most grandparents - especially in the majority culture-anticipate an empty nest in their latter years of life, where their focus shifts from primary caregiving and breadwinning duties to retirement planning and community and recreational activities (Feldman, 2005). For grandparents rearing grandchildren, they must make the shift from moving towards an "empty-nest” back to primary caregiving parent. Such a transition is considered non-normative and off-time, according to societal expectations of being a grandparent (Landry-Meyer, 2004), and may result in new personal and familial challenges.

The shift from empty-nester to primary caregiver can be seen in the Hatfield's story. Mr. and Mrs. Hatfield (57 and 59 years old, respectively) had been married for 36 
years and reared 4 children; they had been experiencing an empty nest for 3 years. Their son had two daughters with a woman who subsequently began to struggle with substance abuse and started abusing and neglecting the children. Custody was given to the father, the Hatfield's son; while he had intentions of caring for his daughters, his work schedule made finding childcare impossible. It became evident that the Hatfield's had the resources to better care for the girls than their father. The granddaughters (aged 7 months and 2 years) then moved in full-time with their grandparents. As Mrs. Hatfield stated, “We were used to peace and quiet. [We] didn’t have anybody here. [We were] coming and going whenever we wanted. [We went from] quiet to chaos.” As is the case for many grandparents who take on the surrogate parental role, grandparents have to make swift shifts in their day-to-day routines in order to meet the demands of their grandchildren.

The abruptness of the Hatfield's role change was echoed by another grandparent couple, the Maxwell's, who were younger grandparents at the ages of 36 and 41 years, yet looking forward to retirement life without children. They were planning to travel in the coming child-free years when they found out that their 18-year-old daughter was pregnant. Mrs. Maxwell’s daughter dropped off the young grandson regularly for months at a time and left with no contact. The Maxwell's took over primary care responsibilities when at the age of three, his mother made him pack his belongings before she dropped him off at his grandparents’ home for good. Mr. Maxwell explained that, although they had highly anticipated that their grandson would some day be living with them full-time,

We just didn't know it would take place at such an early age. We thought maybe eight or nine, ten years of age before it happened, but it happened sooner than we thought, so even though we 
expected it, it kind of caught us off guard, and then we scrambled. We're fine now, but it took us quite a while to figure out what we had to do. We had days off for years; we switched those so we did a lot of things differently to try and make this work.

Mrs. Maxwell further explained:

We were at a point where our kids were older. We were going out. We were traveling. We were doing whatever we wanted, whenever we wanted, and all-of-a-sudden, everything comes to a screeching halt because now you've got this [young child] that needs care and, you know we had alone time, and now we don't have alone time. It's a huge adjustment.

This adjustment from life without children back to a home with children was a challenging lifestyle and role shift. Grandparents who took over the surrogate role for grandchildren who had experienced traumas early in their lives reported that they not only had to shift from grandparent to primary caregiver, but they also had to make shifts in their roles as breadwinners for their families.

\section{$\underline{\text { Full-time Employee to Stay-at-Home Parent }}$}

As grandparents shifted their roles to meet the needs of their grandchildren, many quickly realized that their grandchildren needed significant care, and many either could not afford child care costs or felt their grandchildren needed significant time and attention to help them heal from earlier traumas. The special needs of some grandchildren stemming abuses by their parents also created distinct challenges in sustaining employment for grandparents. To adjust, many grandparents shifted their work and family obligations - opting to leave their careers to stay at home with their grandchildren. 
As an example, the Barkers, both in their fifty’s, had been caring for their three grandchildren — ages ten, eight, and five years — for 3.5 years. All of the grandchildren in their care had suffered from years of parental abuse. Mr. Barker lamented about the first months after their three grandchildren moved in, stating, "there was a time when we both sat here and basically we went into hiding with just the kids because everything was so overwhelming.” Mrs. Barker further shared, "When we got the kids there was no way we could have left them with anybody.” To best care for their grandchildren, she decided to stay home to nurture them as they adjusted; she therefore retired from her professional career in the healthcare industry, giving up a \$55,000 annual salary and health care benefits.

Grandchildren with special needs required more attention, which posed problems with finding childcare and created barriers to maintaining full-time employment. Ms. Walker, a 45-year-old, single, custodial grandmother had been caring for her 4-year-old granddaughter with severe disabilities at the time of the interview. Ms. Walker shared that when she took over the care of her granddaughter, she could not find childcare that would take her granddaughter due to her disabilities. In addition, although Ms. Walker tried to balance work and family, her ability to work a full-time job interfered with her ability to take her granddaughter to her bi-weekly physical therapy sessions. Ms. Walker consequently had to quit her job. She reflected:

My girlfriends tell me "If that was happening in my life, I'd just lie down and cry." Well, granted, sometimes I do, but I'm not going to let it kick me in the butt. I have to keep on keeping on for not only me but for her. 
For grandparents who quit their jobs, adjusting to full-time childcare was a challenge. Mrs. Pierson, a married grandmother who had adopted her 2-year-old grandson, stated that she had to quit working because of the costs of childcare. She spoke of her experience as a stay-at-home mother, “It’s hard, very hard. I don’t have a babysitter and he’s never been with daycare. It just keeps me busy 24/7 and sometimes there's times when I just need a break.” She spoke of the frustrations that also came with the social isolation of having no family in the area to go to for support. Ms. Pierson admitted that “I don't have patience, so it goes all day every day, and there are some days that I just need a break.”

For many grandparents in this study, finding a balance between work and family was difficult. To adjust, some grandparents_and mainly grandmothers—shifted their roles from wage earner to stay-at-home caregiver to best meet the needs of their grandchildren. And while this shift seemed best for their families, some grandparents struggled to adjust to their "new” roles as second-time-around parent.

\section{$\underline{\text { A Second Chance to Parent }}$}

One emergent subtheme that was shared by nearly all grandfathers in this study was their opportunity to shift from their traditional familial role of breadwinner to caregiver of their grandchildren. When asked about their new roles as primary caregivers, nearly all grandparents shared that they felt like they were better parents now then when they were rearing their biological children. However, for grandfathers, this shift seemed in some ways more profound. Grandfathers lamented that, when their own children were 
young, they were working hard to provide and missed out on many of the joys of parenthood. However, parenting a second time around presented grandfathers with a second chance to bond with and socialize their grandchildren. Because many families reported being better off financially than they had been in the past, grandfathers appeared to be less burdened with breadwinning, which left more time and resources for caregiving.

This shift is exemplified by the story of Mr. Colins, a 54-year-old grandfather who had adopted all three of his grandchildren. Mr. Colins shared that when he was younger, he was busy being a "breadwinner" for his biological children. His wife stated that when their granddaughter was born, "It was the first opportunity he had to bond with the [grand]child, because he had never been there for the birth of any child, or to know what that felt like. He was the first one to hold her.” Mr. Colins concurred:

I missed things because I was working. I never did bond with those three kids. [I] had them in my heart, but nothing like with [our granddaughter]. [Having her] was just like having a child, and all those things I seen her first do this or do that.

Grandfathers like Mr. Colins seemed to bond well with their grandchildren, and had the opportunity early on to establish their bonds. This early bonding may be important to grandfathers' shifting their familial roles to perform caregiving duties in their families. This early bonding can be seen in the story of Mr. Eubank, who initially rejected his teenage daughter's newborn son; however, when he held his infant grandson for the first time, he seemed to experience a significant shift. Mrs. Eubank shared, "From 
that day on, they were inseparable. I mean, that was his 'Poom-Bah.' He lived for that child. He said, ‘Don’t ever tell him that I didn’t want him.'”

On the other hand, not all grandfathers in this study had experienced biological parenthood. For Mr. Pierson, whose stepdaughter became pregnant as a teenager, grandparenting with his wife was his first experience in a caregiving role. Mrs. Pierson talked of the relationship between her husband and their 2-year-old adopted grandson. “They are so close that you wouldn’t believe it. [My husband] just dearly loves [our grandson], but he’s never had children, so they are very, very tight.”

In sum, grandparents in this study reported that they had not planned on parenting again, but had taken on the parenting role in an effort to keep their grandchildren safe and to nurture their healthy development. Overtly, grandparents were performing parenting duties; yet the grandparents' identities as grandparent or parent seemed to be a matter of interpretation. Whether or not grandparents shifted their identities to "match" their roles appeared to depend on several factors, as discussed below.

\section{$\underline{\text { Shifting Identities }}$}

For grandparents in this study, role shifts were necessary given the external demands placed upon their families; however, the internal identity shifts were less clear. For some grandfamilies, identity shifts seemed to be related to the age of the grandchildren. For example, grandparents with older grandchildren (e.g., adolescents) often shared that their grandchildren knew who their "real" parents were and knew who their grandparents were. In these families, grandparents held fast to their identities as 
grandparent caregivers and did not shift_-and this was perhaps in the best interest of the child. However, for grandparents of younger grandchildren, there appeared to be two kinds of shifts. Some grandparents appeared to accept their grandchildren as their own children and became "Mom” and "Dad,” whereas others seemed to experience identity ambiguity.

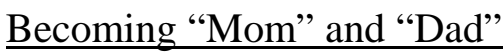

As grandparents were shifting their roles to perform the surrogate parental role for their grandchildren, there appeared to be —-for some - a parallel shift in their identities from "grandparent” to “parent.” Becoming “Mom” and "Dad” was perhaps most apparent in the four grandfamilies in this study who had adopted their grandchildren. In these families, the grandchildren were all quite young and the biological parents' rights to their children were terminated by the courts, allowing the grandparents to legally adopt their grandchildren. For other grandparents, adoption wasn't necessary for them to make the shift from grandparent to parent. For example, Mr. and Mrs. Franklin, who were in their sixty’s, had guardianship of their 6 and 7-year-old granddaughters for four years. As Mrs. Franklin shared, "They really are our kids...I prepared myself saying these are the best things for these girls. This is where they belong. They don't belong anyplace else. They belong here.”

Ms. Goodman, a 67-year-old grandmother who had guardianship of her 11-yearold granddaughter since her granddaughter was an infant, also related her shift to parent when she said, “It just kind of happened. Once a mother, always a mother, I guess. It’s 
not something I really wanted to do, raise my grandchild. I’ve already gone through that.” And while Ms. Goodman may have at times been ambivalent about her role as mother, she clearly began bonding with her granddaughter early on. According to Ms. Goodman:

I think that because I've been there since she was born it was totally easy. She was itty-bitty; she was in a backpack on my back. We bonded since day one, I'd say, and she's been a delight the whole time.

For other grandparents, the identity shift appeared to come after everyone had settled into their new roles. As can be seen in the following example, Mr. Barker described his epiphany of realizing he was no longer a grandpa. His transition took several years.

It took us the first two years of this whole thing to realize, and conversations with each other, that wait a minute, we've finally got to quit being grandparents. We can't be grandparents anymore. We're now parents. And there is a mental thing in there. You have to physically say "hold it, I'm doing this wrong. I'm trying to be grandpa.” I can’t be grandpa and that is a hard thing for grandparents to give up. And I don't know if that is something other people talk about, but that was absolutely a monumental conclusion on our part.

While many grandparents in this study seemed to make a clear shift in their identities from grandparent to parent, others were less clear. In such cases, grandparent identities seemed to vacillate or seemed to be dictated by their grandchildren. In other words, their identities were more ambiguous.

\section{Identity Ambiguity}

Many grandparents in this study seemed to feel caught between two identities; functionally, the grandparents were parents to their grandchildren, however some resisted 
giving up their grandparent identities or were slow to embrace the idea of being "Mom" or "Dad” to their grandchildren. In addition, some grandparents were more passive in their approach, allowing the grandchildren to decide their identities for them. As can be seen in the following example of Mrs. Stevens, who along with her husband, had fulllegal custody of their 5 1/2-year-old twin granddaughters. She shared:

They call me "Grandma," they call me "Mom," they call me "Mommy." Depends on what's going on at the time. My husband is "Papa." There have been rare occasions when they call him "Daddy,” but it's basically "Papa.” My daughter and I have gotten into arguments over this and I flat told her, "They call me what they want. I've been there from day one. I'm the one that's rocked them in the middle of the night, fed them in the middle of the night. I'm the one that's been there when they've been sick and they can call me what they want to.

Mr. and Mrs. Jensen, who had Power of Attorney over their 4 and 5 year old grandchildren, also stated that they get called "Mom” and "Dad” occasionally. Mrs. Jensen stated, “We don’t knock it because we know who we are.” Mr. Jensen added, “We always refer to ourselves as ‘Grandma’ and ‘Grandpa.’ Though Mrs. Jensen concluded, "We are not going to say, 'call us Mom and Dad' either.”

Mrs. Eubank, who had been rearing her grandchildren for 14 years, echoed many grandparents when she shared her thoughts about her current situation and the resulting identity ambiguity that often emerged in these family constellations. She stated, "You can’t be a grandparent to these kids because you're raising these kids. I mean, we were grandparents, but we were also parents again....At times I forget that I am a grandparent and I'm the parent, so it's hard.” Mrs. Hatfield likewise shared her thoughts about her identity and the ambiguousness of her position when she said: 
They're not mine. They belong to my son and so there's a lot of responsibility that I would not normally have. The other thing that I think really affects me is I can't be just Grandma. That's hard. I have to be "Mom." I have to be the disciplinarian. They can't come here and it's just sugar and sweet and all that stuff that grandkids do. (My grandkids) will call me “Mom”....I don’t care what they call me. It doesn't matter. Now the girls, I don't like being called “Mom.” I don't particularly care for it. It's not right. I'm not their mom. I'm their grandmother. I like being a grandmother, and it's just that I'm put in another role.

Although Mrs. Hatfield appeared to struggle with her identity, the particulars of whether her grandchildren call her "Mom” or “Grandma” seemed to be of little importance in relation to her function of providing safety and nurturance for her grandchildren. Her identity seemed to be driven by her grandchildren's needs and what they needed her to be on different occasions and in different circumstances.

As grandparents shifted their roles and their identities to accord with the emergent needs of their grandchildren, such shifts appeared to also influence the ways in which grandparents related to their adult children and others in their network. Next, we examined how grandparents shifted relationships as they adapted to parenting the second time around.

\section{Shifting Relationships}

While grandparents discussed shifts in relationships with the extended family and communities, perhaps the most difficult shift for many was the "letting go" of their adult child who was either unwilling or unable to parent. 


\section{Letting Go of the Parents}

The repeated, and often failed, efforts to help their children get it together and regain their parenting role appeared to exhaust many grandparents' patience and hopes. Mrs. Dixon, a 46-year-old grandmother who had been rearing her 5-year-old grandson since infancy spoke of her lost hope for her daughter who had been in jail repeatedly. “I kind of stay away from her anymore. I broke myself off. It can’t be fixed... I can't deal with it no more. I got him to raise. I can’t deal with her.”

For Ms. Ross, dealing with her daughter's problems required more energy than she could spare; subsequently, she also made the painful decision to stop engaging with her.

This is a sad thing to say, but I pretty much had to give up on her and focus what energy I have on him. I can't care about where she is living. I can't care about what she is doing. If I did, I get physically ill from the stress and I end up in bed, sick in bed. So I've just had to say, 'Okay, I just can’t worry about her'....you can only dig so deep before you run out of stuff and so I've got to focus what I've got in him.

For other grandparents, the decision to truncate their relationship with their adult children was endorsed by professionals. Mrs. Maxwell lamented, “The counselor told us to stop contact [between the mother and grandson] because she was doing more harm than good.” Grandparents who felt they had to "let go” of their custodial grandchildren’s parents appeared to do so for self-preservation and for the well-being of their grandchildren.

Other grandparents resolved their relationships with their custodial grandchildren’s parents in a more open-ended manner. Ms. Goodman, for example, 
talked about coping with the decision to stop worrying about the mother of her custodial grandson when she stated:

I've learned a lot, like you got to keep a positive attitude about whatever happens. There's only so much you can do. You cannot change the other person, in no way, shape, or form. They have to do it themselves. I've always been there for her. It's like the door has always been open, the phone line has always been open for her to call me. I may not be able to do anything, but I can still say, "I love you."

For many grandparents, the loss of hope that their adult children would or could "get it together" seemed to enable them to focus on meeting the needs of their grandchildren. It is possible that this shift, this letting go of the parents, also related to role and identity shifts as well as shifts in other familial and community relationships.

\section{$\underline{\text { Shifting Family Relationships }}$}

Taking over parenting roles from their adult children presented new challenges for many of the grandparents. Some grandparents reported jealousy and resentment in their other adult children. Mrs. Barker stated that her adult son "was a little angry with us, a little put out with us for allowing this to happen.” Mr. Barker added, "It was like we should have been more cold-hearted and [used] tough love. But you know, you try really hard not to.” Mrs. Barker continued to say:

We don't feel like we've made this happen, but [our adult son] says, "why did you give her [our adult daughter, mother of our custodial grandchildren] that" or "why'd you let her do that." He just couldn't understand how come we were helping her, but we were hoping that somehow her life would turn around, but it just wasn't never to be. 
This experience of jealousy within the family was echoed by the Franklins’ story. Mrs. Franklin, referring to her other adult son, stated, "He is jealous because he sees the (grand)kids get more. Because we do have a little more than when they were (kids)...we've come a little further, we're making a little more money.” The grandparents went on to explain that their other adult daughter is also jealous, but for different reasons. Their adult daughter had noticed the differences in attention that her kids get versus the attention enjoyed by the custodial grandchildren. The grandmother empathized with her daughter, but also felt that she was going to have to "come to grips with it....I'm assuming they will at some point. That's all they can do. Either that, or feel like that for the rest of their lives because they're [the grandchildren are] going to be here. There's no doubt about that.”

Other grandparents in this study reported anger and resentment from their adult children. Some adult children felt that the grandparents should not have been rearing the grandchildren. The Gavin’s, for example, were not supported by their adult children in their decision to rear their two granddaughters. The family had an intergenerational history of sexual abuse, leaving complicated, unresolved issues between the family members. Mrs. Gavin said of her adult children:

They do not like it at all, not one positive thing. They are not talking to us much. [My daughter] and I talk every week and we've had some fun outings, but after the big family discussions they just said "We don't want to know how the girls are. We don't want to know how [the granddaughter's father] is. We don't want to hear; we don't even want to talk about them in our presence." So when she and I are together, because I'm a motor mouth, I have to swallow my words. I can't go there. 


\section{$\underline{\text { Shifting Community Relationships }}$}

Grandparents also shifted how they related to members of their communities and larger institutions (e.g., education, social services). Researchers have noted a lack of mores, norms, and traditions upon which grandfamilies might draw in order to make sense of their circumstances and a lack of extended kin network supports available to facilitate their family functioning (Bowers \& Myers, 1999; Hayslip, Shore, Henderson, \& Lambert, 1998; Jendrek, 1994). Rearing grandchildren within a non-normative framework or life course stage may conflict with the familial structure and normative framework expected by the larger society.

The lack of understanding by community members was mentioned as a consequence faced by these grandparents. However, several mentioned that they adjusted by communicating openly with community and institutional representatives, such as school counselors and teachers. For example, one grandmother, Mrs. Arnold, who had been rearing her 10-year-old grandson and 2-year-old granddaughter, talked about how she handled her grandson's teachers (and essentially re-socialized them to better meet her

“non-normative” family’s needs) when she said:

I went in and did all the way through elementary, met with his teachers ahead of time to train them a little bit about his background. [I told them] "If you're going to be talking about moms and dads, he doesn't have a mom and dad. Well, he does, but they're not in his life, so it's going to have to be 'grandparent,' or it's going to have to be 'grandma' or 'folks' or 'parent.'

Another grandmother, Ms. Tomkins, a widowed grandmother who had been caring for her adolescent grandchildren for about six months, said she was motivated to 
start communicating with her 13-year-old grandson's school so she could access his grades. She said, "He had tried very hard in school to not even let them know there was a problem with his mother’s drinking. He simply doesn’t want it to follow him any further.” The counselor and teachers had been watching the grandson carefully all year, suspecting something was amiss. Ms. Tomkins explained:

[The school was supportive] once I told them, but their hands are tied because I have no legal papers, but the dad did get the grades sent here. The one day that [my grandson] needed to be picked up from school, the dad finally got it okayed and said, "We can go get him.” It just has been a hassle for this kid.

These grandparents found that being proactive by communicating with and training the teachers about their unique family situations was imperative as the grandfamilies adapted.

Unfortunately, some grandparents did not feel supported by their larger community, which also necessitated relational shifts. For example, the Hogan’s, a grandparent couple in their sixty’s, stated that they did not feel community support in their efforts to rear their grandson, which left them feeling isolated. Mrs. Hogan explained, “The community thought we was crazy for raising him.” She continued, “I don't think they thought he would do good because being raised by grandparents instead of his mother I guess.”

Mrs. Costello, a 71-year-old grandmother who had been rearing her two grandsons for eight years, was keenly aware of the stigma of rearing grandchildren but also was aware of the consequences of not taking in her grandchildren. She stated, "People say to me all the time, “Oh, I would never do that.” I say, "Yeah you would. If you had an opportunity to raise one of your grandkids, you would do it rather than having 
to go through Family Services.” The shifting of community relationships was apparent as the grandparents educated school systems and related to their peers. While not all members of their communities supported or understood the grandparent's efforts, the grandparents seemed to make a shift in how they related to the community. Another shift emerged from the interviews as the grandparents explained how they shifted finances and learned to navigate government programs in search of assistance.

\section{Shifting Resources}

After the initial crisis phase, when grandparents began the process of coping with the immediate psychological and physical demands of rearing their grandchildren, grandparents appeared to seek out and acquire new resources from the external contexts to meet the inevitable pile-up of stressors that occurred over time. Grandparents often had to struggle with the cumulative effects of financial, emotional, and physical stressors, which appeared to motivate them to explore new resources. Finding adequate resources was more complicated for some grandparents than it was for others depending on their internal resources (e.g., positive outlook, faith, flexibility, communication style) and perceptions of the availability of external resources (e.g., family, friends, church, government programs).

\section{Shifting Finances}

As they adjusted to primary caregiving, the grandparents in this study reported that their financial resources were necessarily shifted from themselves to meeting their 
grandchildren’s needs. Grandparents incurred many unexpected costs as they adjust to rearing their grandchildren by shifting financial responsibilities from saving for their retirement years to paying for the grandchildren's needs and activities. For example, the Olson's, who were both in their forty's, had been caring for their infant grandson for five months and were expecting the arrival of two granddaughters (aged 4 and 2 1/2 years). Mrs. Olson stated:

At this point, we're just kind of waiting to see what's going to happen [with our retirement plans]. It's been a little bit harder financially.......the bills have gone up a bit, changed the grocery habits. I mean, I haven’t bought animal crackers and juice boxes in years. In the back of our minds at night it's like "Oh, how long do you think they're going to be here?”

Financial strains were commonly mentioned by grandparents in this study.

However, the costs of childhood activities and basic needs were not the only costs incurred by the grandparents; many grandchildren required medical and dental care. The Gavins, who are both in their fifty’s, had been rearing their 8 and 6-year-old granddaughters for two-and-a-half years. Mrs. Gavin stated:

We had saved for a down payment on a house, but we couldn't (save money) from the time (the granddaughters) entered the picture for like three or four months. There were just so many needs when we got them. We've paid \$1,000 probably each with dental bills because they had cavities up the gazoo and one needed glasses, and just all those things.

Mrs. Gavin went on to say that "There were a lot of out-of-pocket expenses. I mean hundreds and hundreds of dollars.” Other grandparents reported using up their savings to care for their grandchildren. The Stevens,' who are also in their fifty’s, stated: 
We've depleted our savings. I don't see it any differently than if they were my own biological kids. You dip into your savings for different things. Hopefully, by the time they're ready to go to college, we'll have that situation taken care of.

While the shifting of resources was challenging for grandparents, the rewards of rearing their grandchildren seemed to negate the negative. Maintaining hope that things will work out in the future was a key adaptive strategy employed by many grandparents as they faced financial turmoil. Others pursued assistance from government programs.

\section{$\underline{\text { Acquiring Formal Services }}$}

Depending on the sources of the stressors and the severity of the traumas experienced by their grandchildren, grandparents appeared to utilize different resourcesor orchestrated the employment of a combination of resources - to meet the needs of their grandfamilies. Counselors and teachers offered insight, reassurance, and advice for managing psychological stressors, which resilient grandparents appeared able to receive and internalize in meaningful ways. Grandparents also became aware of and utilized valuable community resources, government programs, and other social supports for mitigating their financial or psychological stressors. Four grandfamilies in this study reported receiving Temporary Assistance for Needy Families-Child Only grants (TANFChild Only), three received Medicaid, and four families had received Women Infants and Children (WIC). Medicaid was the government program utilized most often by the grandfamilies. Unfortunately, for the majority of grandfamilies in this study, accessing formal, government-based resources was challenging because many did not know of the programs or were not eligible because their household income levels were too high (i.e., 
above the poverty threshold). Such was the case for the Maxwell's when they began to seek out assistance:

We didn't really know where to turn to when this was happening, because we really didn't fall under any aid. Or we didn't know of any aid that was available. It's not really that we needed it, but we didn’t know what to do or where to look, or where to turn to.

After they had discovered how to apply for assistance, Mrs. Maxwell learned that her family was not eligible. As she commented:

We don't qualify for any aid. We make too much money, but they don't take into account that you have a house and in order to qualify for any aid, you have to literally liquidate all of your assets. So we're like, “Oh forget that.” You don't work your whole life in order to just have to turn around and liquidate everything you've worked for. That's asking a very unfair thing of people.

Because the phenomena of grandparents rearing their grandchildren is still quite new, institutions have not yet caught up with these families and have not made the shifts these grandfamilies seem to need in order to best meet the needs of their members. As Boss (2002) notes, because families do not have control over external forces in their lives, shifting perceptions and gaining control over what they can control —-those internal forces—often is critical to positive adaptation.

\section{Shifting Perceptions}

The more able a family is to redefine their situation, the more prone the family will be to successfully adapt to the demands being placed on them (Boss, 2002). Regardless of the persistent non-normative stressors of parenting one's grandchildren, the sentiment that rearing their grandchildren was a positive event in their lives was 
ubiquitous throughout the interviews with the grandparents. Thus, a new meaning put on the situation may have changed the context of the grandfamily's coping resources.

As Mrs. Arnold, a 55-year-old grandmother who had adopted two grandchildren, a 2.5 year old girl and a 10 year old boy, said:

Well, it has really been a blessing for me. I don't think most people get a chance to be as close to their grandchild as I do. He is a really special kid and so I really feel really blessed with having him.

Mrs. Hatfield, although admitting having feelings of loss for her grandmother role, reflected:

There's so many rewards in raising grandchildren, so many more rewards than negatives, there always will be. They biggest thing is, don't look back on what you had and what you could have had, had this not happened. That you just can't do. To me, it's a reward, it really is. I guess I can honestly say I wouldn't trade it for the world.

While this grandmother missed being a grandmother to her custodial granddaughters, she was able to reframe her perceptions of her situation and concentrate on the future, as opposed to ruminating over what could have been.

Although the average age of the grandparents in the study was over the traditional age for childrearing, many grandparents perceived their age to be an advantage. Mr. Barker, who was 57 years old, stated, "I would not trade a day in my life right now for anything I had before...we're fortunate because we are still young enough. There are grandparents out there who are a lot older than us; that's harder for them than it is for us." Mr. and Mrs. Jensen, both in their sixty's, concurred with a feeling of being fortunate and that being older rearing their grandchildren was perceived as strengths. "I think [he] and I 
are lucky because we're not working. We are retired. We have more patience. We have more money then we did when our kids were young,” Mrs. Jensen said. By redefining their non-normative circumstances as positive, the grandparents appeared motivated to persevere regardless of their internal and external challenges. Therefore a key adaptation process for resilient grandparents in this study appeared to be the ability to shift their perceptions of their situation and adapt to their new family constellations. As Mr.

Hamilton, a 54-year-old grandfather who has been rearing his 8-year-old grandson since he was an infant, stated:

I never felt burdened. I've been angry with her [the mother] before for not owning up to some responsibilities, but never ever felt burdened. In fact, I feel very fortunate to have [my grandson], never burdened. It's really been a benefit in my life. It's more of a gift; it's something that happened to me. 


\section{CHAPTER 5}

\section{DISCUSSION}

The purpose of this study was to better understand how grandparents rearing grandchildren adapt to their new family constellations. Because much of the extant literature has focused on the challenges faced by grandparent caregivers, this study aimed to shed light on adaptive pathways that may lead to grandfamily resilience. Guided by the theoretical work of McCubbin and Patterson (1983) and Boss (2002), this study examined the ways in which grandparents coped with their familial crises and utilized resources to best meet the needs of their grandchildren. This study also considered internal and external contextual factors that may facilitate or hinder grandparent coping, resource acquisition and adaptation (Boss).

Findings suggest that grandparents rearing grandchildren without a biological parent present make a series of shifts in their lives in order to adapt to the changes in their families. Shifts included shifts in their familial roles; their identities as grandparents and parents; their relationships with their adult children and social institutions; their resources (e.g., finances, government assistance); and their perceptions of their familial situation. Consistent with McCubbin and Patterson’s (1983) Double ABCX Model, grandfamilies in this study experienced crises that required grandparents to shift their resources (the Bb factor) — especially their financial resources_-as well as their perceptions of the situation (the Cc factor) or the ways in which they made meaning of their familial circumstances. This study made a unique contribution to the literature by also identifying how custodial 
grandparents shift their roles, identities, and relationships within their families. Because of the non-normative nature of their familial situation (Landry-Meyer \& Newman, 2004), grandparents had to make adjustments that most families confronting crises do not typically have to make.

First, this study found that grandparents had to shift their roles to meet the emergent needs of their grandchildren. Immediately upon taking in their grandchildren, grandparents' future plans changed. They necessarily shifted from planning for their retirement back to being primary caregivers of children. Depending on the special needs of the grandchildren and grandparents' financial abilities to afford childcare, some grandparents—and especially grandmothers—opted to leave their jobs to focus solely on meeting the needs of their grandchildren. Because many grandchildren in these family constellations have experienced abuse and/or neglect by their biological parents (Geen, 2004), grandchildren often exhibit significant socio-emotional or behavior problems. Many grandparents in this study had difficulties finding childcare that could address the developmental problems of their grandchildren or adequately meet their grandchild's special needs.

While primary care provision in most grandfamilies typically falls on grandmothers, this study also found that grandfathers may take a more active role in the caregiving than fathers do generally. Almost all the grandfathers in this study experienced significant role shifts in their families. For many grandfathers, they lamented that they missed opportunities to nurture and socialize their own biological children because they were focused on their bread-winning responsibilities. When grandparents 
intervened in their grandchildren's lives, however, grandfathers appeared to get a second chance to parent. During the interviews, both grandfathers and grandmothers discussed the special bonding that occurred between grandfathers and their grandchildren. This bond seemed especially apparent in cases where the grandparents took over the parental role when their grandchildren were in their infancy or were toddlers. Grandfathers not only made shifts in their familial roles, but also appeared to shift their identities to accord with their new opportunities to nurture and socialize young children.

Shifting identities emerged as an adjustment experienced by both grandmothers and grandfathers. Indeed, this study found that once grandparents shifted their roles, many experienced identity shifts that accorded with their new roles. Most often, grandparents discussed shifting from being grandparents to being parents. These role and identity shifts may be similar to the adaptation processes of adoptive families more generally; however, grandparents are in a very unique situation. They are being asked to step out of their normative, socially constructed roles as grandparents in order to perform a surrogate parental role for their grandchildren. It appears that for many grandparents they are breaking new ground; "normative” grandfamily coping strategies (or "road maps" for positive grandfamily adaptation) have not been established or addressed in the extant literature and few resources exist to help grandparents and their extended family system transition to grandfamilies.

While some grandparents were able to "become Mom and Dad" to their grandchildren, others appeared to struggle with their identities. Based on the stories of many grandparents, it appeared that their identity shifts were driven by how the 
grandchildren identified the grandparents. Some grandparents acknowledged feeling confused about their roles and subsequent identity; functionally, they performed parenting roles, but they continued to feel like grandparents or to pine for the lost grandparent role. Grandparents who had their grandchildren from infancy had more time to bond and to establish a new identity. These grandparents were more likely to identify themselves as parents.

Beyond identifying emergent shifts in grandparent roles and identities, this study also found that grandparents shifted their relationships within their families and communities in order to best meet the needs of their grandchildren. In shifting their family relationships, some grandparents made the painful decision to "let go" of their adult children who were struggling with substance abuse problems or mental health problems that interfered with their ability to positively parent their children. The added stress of worrying about the well-being of their adult children was too much for some grandparents, especially for those who witnessed their children repeatedly fail to regain sobriety or manage their illness. These grandparents appeared to lose hope that their children would ever "get their acts together" and be able to take over their parental responsibilities. It is possible that for some grandparents, this loss of hope was necessary for them to fully transition to become parents to their grandchildren. Thus, it is possible that those grandparents who were struggling with their identities were also holding out hope that their adult children would recover and that the grandparents could return to their roles as grandparents. Holding out hope may have resulted in what Boss (2002) refers to as an ambiguous stressor. According to Boss (2002), living with an ambiguous 
stressor, such as not knowing if you will remain a parent to your grandchildren or be able to return to grandparenthood, is more difficult to deal with than a "clear-cut" stressor. Those grandparents who "cut off” their adult children, shifted their roles to primary caregiver, and shifted their identities to "Mom" and "Dad," may have found relief from the ambiguity of not knowing how to be in the lives of their grandchildren.

While grandparents made multiple shifts in their roles, identities, and relationships, their adaptation to their surrogate provider role also necessitated shifts in resources and their perceptions of the situation (as suggested by McCubbin and Patterson’s (1983) work). It is well documented in the literature that many custodial grandparents struggle financially when they take in their grandchildren (Emick \& Hayslip, 1999). Unfortunately, there are few government-based resources available to support these families (Geen, 2004; Pinson-Millburn et al., 1996)—as was the case with the families included in this study. Thus, many resilient grandparents likely have to look inward or internally and find the strength to cope with the resource challenges faced by their families.

Boss (2002) has suggested that shifting perceptions of the situation is critical, especially when grandparents have little control over the external forces (such as limited government supports) that exist in their lives. In this study, some grandparents who were disadvantaged by the unavailability of resources in the external context, successfully made shifts within their "internal context” (e.g., psychologically, philosophically) and were able to reframe their familial situation to the positive. This reframing or shifting of perceptions appeared to support grandfamily bonadaptation (McCubbin \& Patterson, 
1983). When grandparents resisted shifting their roles, identities, relationships, or resources - trying to maintain their “old” family patterns - they appeared to get "stuck" in their adaptation process and seemed to struggle more than those grandparents who were making successful shifts and adjustments in their lives. While this study cannot definitively speak to the bonadaptation or maladaptation of the grandfamilies, findings suggest that resilient grandparents were those who could successfully negotiate their new family circumstances and make requisite adjustments and shifts in order to meet their needs and the needs of their grandchildren.

\section{Study Limitations and Future Research}

While this study offers additional insights into the processes employed by grandparents as they cope with their familial transitions and crises, it is not without limitations. First, this study was limited by a small sample size. While it is likely that this study captured many common adaptations employed by grandparents rearing

grandchildren, a larger, more diverse sample might yield additional coping strategies and shifts in grandfamily functioning. Because a purposive and snowball sampling strategy was employed, we are limited in our ability to generalize to others grandfamilies. Findings suggest several ways in which resilient grandfamilies adapt to familial crises and traumas. However, future research is needed to continue to delve into grandparent processes and to better understand pathways to resilience among more diverse grandfamilies. 
For example, we know little about adaptive processes among Native American grandfamilies. Because of our convenience sampling strategy, we did not interview many Native American grandparents, yet in Montana, 6\% of the population is comprised of Native Americans (U.S. Census, 2000). Given the history of Native American families, in which grandparents typically played a salient caregiving role in the lives of grandchildren, it would be interesting to explore the intergenerational relationships and coping processes among these families. It is likely that Native American grandfamilies function quite differently from European American grandfamilies. Native American grandparents who live on reservations likely have access to different resources and likely most cope with different internal and external contextual factors as they rear their grandchildren. Future research should shed light on pathways to resiliency among diverse groups of grandfamilies, including Native American and other minority groups.

Another limitation of this study was its scope. Future research might consider interviewing multiple generations of a grandfamily system to understand the impact of familial crises from different generational vantage points, as well as resource acquisition and perceptions of the situation. Future researchers of grandparents rearing their grandchildren might also consider looking further into the impact of the characteristics of the grandchildren on family coping processes. Many grandchildren being reared by grandparents likely have experienced significant trauma associated with abuse, neglect, or abandonment by their biological parents. The major reasons for grandparents rearing grandchildren in this study included substance abuse and mental illness. How grandchildren cope with histories of trauma and possible attachment disorders would be 
important to understand, particularly if researchers want to intervene on behalf of these grandchildren.

And lastly, future researchers should continue to investigate grandparents raising grandchildren in rural communities using larger sample sizes that will allow for more complex analyses. Because many rural communities are likely to experience drug use problems such as methamphetamine (Ciliberti, 2000), more attention should be given to meth-related problems and how they are affecting grandparents - who are often the only individuals available to take custody of their grandchildren given the limited number of foster care families in rural locales. Researchers might also consider expanding the ecologies examined in future efforts by examining other macro-level variables, such as social and economic policies and family laws relevant to kinship care (which can vary by state and tribal nation). Adding other micro-contextual variables, such as child characteristics (e.g., special needs, developmental disability of the grandchild, physical limitations, and behavioral disorders that the grandchild may exhibit) and intergenerational family relations (e.g., between grandparent and parent, parent and child, and grandparent and grandchild) will also be important to fully understanding the adaptive processes of grandfamilies.

\section{Implications for Practitioners and Policymakers}

Beyond research considerations, there are a number of implications for practitioners and policymakers who focus their efforts to improve the functioning and well-being of grandparents rearing grandchildren. Given the often tragic circumstances 
that necessitate grandparent involvement, the difficulties experienced by the children may exacerbate the adjustments related to middle-aged and older grandparents assuming parental roles (Hayslip et al., 1998). Since internal contextual resources are salient factors for buffering the effects of stress, grandparent caregivers could benefit from mental health services, especially in rural locales where mental health professionals are sparse.

Crises and resultant stressors were influenced by several contexts, including economic, historical, developmental, and psychological contexts (among others). Thus, this study suggests that we must situate grandfamilies in context in order to understand the full extent of the crisis experience. By understanding not only the stressors of grandfamilies, but the genesis of the stressors — whether they be external or internalseems important to how practitioners, clinicians, and family advocates assist these families. For example, if the genesis of the stressor is external, Boss suggests that many families will not be able to do much to change the situation. However, families can be supported in reframing the situation and how they adapt to it. On the other hand, if the genesis of the stressor is internal, practitioners might be successful is helping to support families as they strive to make positive changes in their familial structure, psychological make-up or philosophy.

Family resilience-oriented clinical interventions require clinicians to attend more centrally to the linkages between presenting symptoms (e.g., depression, anxiety) and family stressors, focusing on family coping and adaptational pathways in coping with and recovery from adversity. Such interventions are directed at reducing vulnerability and mastering family challenges (Walsh, 2002). Support groups have been found to be 
opportunities for both grandparents and grandchildren to share their feelings and concerns (Smith et al., 2002). According to Walsh, such approaches can encourage family members to share their stories of adversity, which can eliminate the silence and secrecy around painful or shameful events by building mutual support and empathy.

There are many grandparent support groups meeting in communities across the country. In Montana there are now 15 grandparent supports groups where facilitators were trained by the Montana Grandparents Raising Grandchildren Project through Montana State University's Extension Service. The project was started in 2002 in response to the increase in grandparent-headed households across the state. Grandparents appear likely to benefit from support groups as they share their stories and engender empathy and compassion for each other's situations. Grandparents might also share information about other community supports, advocacy efforts to change local and state policies, and coping skills that have worked for them. The mutual support given and received by members of support groups may be important to the promotion of resilience processes for custodial grandparents.

The legal and financial demands reported by many of the grandparents in this study related to their inabilities to qualify for assistance and their perceived lack of knowledge about their rights as grandparent caregivers. Legal guardianship was required to get health insurance and to gain access to many of the formal social supports such as Women, Infants, and Children (WIC), childcare assistance, health insurance, health care, and Temporary Assistance to Needy Families (TANF). Formal social supports such as these government programs helped many grandparents, but many more did not qualify 
for any assistance. Extant policies precluded those rearing their grandchildren informally from qualifying for assistance. Thus, policymakers might consider changing existing policies in order to widen the net of families eligible for financial assistance and other services provided by the state and federal governments.

Current child welfare and financial assistance policies are targeted towards families who rear children as a normative role. Grandfamilies therefore are not able to meet many of the qualifications for many governmental services. Policymakers should be flexible by taking into account the special circumstances of grandparents rearing their grandchildren. Flexibility in accounting for grandparents’ assets and household income when trying to access social services for their grandchildren could help in the management of familial crises. While grandparents may have an income over the limits for receiving assistance, meeting the unanticipated demands of rearing one’s grandchildren can create considerable financial strain.

Many grandparents in this study complained that they could not find available assistance programs or they found out they were eligible too late. One policy suggestion that has been crafted at the federal level proposes a Kinship Navigation System. Such a system would allow grandfamilies a point of contact when they initially take on the rearing of their grandchildren. This contact point would likely assist grandparents by connecting them to the appropriate agencies and programs that could lend support in times of need.

It is important to note that not all grandparent caregivers are the same-some may have been able to establish legal guardianship outside of the child welfare system and 
may not be in need of financial assistance. Nonetheless, as we found in this study, the majority of caregiving grandparents would benefit from assistance with child care costs and access to respite and mental health services. Providing such services to grandparent caregivers and their grandchildren may help these families to better cope with the traumas experienced by familial crises and ultimately support the well-being of informal kinship caregiving families.

\section{$\underline{\text { Conclusions }}$}

Determining the level of adaptability of each of the grandfamilies in this study was a complex task. The intricate nature of the internal and external contexts rendered it difficult to tease apart how each context independently influenced grandfamily functioning and adaptation. As Boss (2002) suggests, the meaning families make of their situations appears to be the root of adaptation. A rather critical moment for many grandfamilies—and for their resilience—occurred when grandparents made the shift from being grandparents to their grandchildren to becoming parents to their grandchildren. For many grandparents, the moment when they realized the importance of rooting their grandchildren in their hearts and homes permanently appeared to lead to additional shifts and adaptations. For example, once a grandparent made the shift to parent, they also were able to reframe family boundaries and address previous ambiguities in familial roles.

This study makes a contribution to the extant literature by examining the adaptation processes grandparent caregivers employ in order to cope with the stressors of taking on the sole caregiving role for their grandchildren. While many studies have begun 
to identify the challenges grandparents face as second-time-around caregivers, few studies have begun to identify the pathways grandparents take as they cope with caregiving and which pathways and contexts facilitate bonadaptation and resilience rather than maladaptation.

Family adaptation is a fluid process in which the grandfamilies continually make adjustments in efforts to achieve a balance between demands and capabilities. All grandfamilies in this study possessed resilient characteristics and thus had potential for bonadaptability. A grandfamily’s level of bonadaptation changes as their stressors, resources, and perceptions change within external and internal contexts. 


\section{REFERENCES CITED}

Amato, P. (2005). Family change: Decline or resilience? In Bengston, V. L., Acock, A. C., Allen, K. R., Dilworth-Anderson, P. Klein, D. (Eds.), Sourcebook of Family Theory \& Research. Thousand Oaks, CA: Sage Publications Inc.

Allen, K., Dilworth-Anderson, P., Klein, D. (Eds.) Sourcebook of Family Theory \& Research (pp. 112-117), Thousand Oaks, CA: Sage Publications.

Billing, A., Ehrle, J., Kortenkamp, K. (May, 2002). Children cared for by relatives: What do we know about their well-being? Washington D.C.: The Urban Institute. New Federalism. Series B, No. B-46.

Boss, P. (2002). Family Stress Management: A Contextual Approach. Thousand Oaks, CA: Sage Publications.

Boss, P. (1980). Normative family stress: Family boundary changes across the life-span. Family Relations 29, 445-450.

Bowers, B. F. \& Myers, B. J. (1999, July). Grandmothers providing care for grandchildren: Consequences of various levels of caregiving. Family Relations 48(3), 303-311.

Bullock, K. (2004).The changing role of grandparents in rural families: The results of an exploratory study in southeastern North Carolina. The Journal of Contemporary Social Services, 85(1), 45-53.

Bullock, K. (2005). Grandfathers and the impact of raising grandchildren. Journal of Sociology and Social Welfare, 33(1), 43-59.

Burnette, D. (1999). Custodial grandparents in Latino families: Patterns of service use and predictors of unmet needs. Social Work, 33(1), 22-34.

Burnette, D. (1999). Social relationships of Latino grandparent caregivers: A role theory perspective. The Gerontologist, 39(1), 49-58.

Caputo, R. (2001). Depression and health among grandmothers co-residing with grandchildren in two cohorts of women. The Journal of Contemporary Human Services, 82(5), 473. 
Casper, L. M., Bryson, K. R. (1998, March). Co-resident grandparents and their grandchildren: Grandparent maintained families. (Population Division Working Paper No. 26). Retrieved November 30, 2005 from the U. S. Census Bureau: http://www.census.gov/population/www/documentation/twps0026/twps0026.html

Chatters, L. M., Taylor, R. J. (2005). Religion and families. In Bengston, V. L., Acock, A. C., Allen, K. R., Dilworth-Anderson, P. Klein, D. (Eds.), Sourcebook of Family Theory \& Research (pp.517-541). Thousand Oaks, CA: Sage Publications Inc.

Ciliberti, E. (2000). Drug use speeds up for youth in rural areas. County News Online. Washington D.C., National Association of Counties. Retrieved April 4, 2007 from http://www.naco.org/cnews/2000/00-9-25/drug.htm

Cohler, B. J., \& Grunebaum, H. (1981). Mothers, grandmothers, and daughters. Personality and childcare in three-generation families. New York: Wiley.

de Toledo, S., Brown, D. (1997). Grandparents as Parents: A Survival Guide for Raising a Second Family. New York, NY: Guilford Press.

Demo, D. H., Aquilino, W. S., Fine, M.A. (2005). Family composition and family transitions. In Bengston, V. L., Acock, A.C., Allen, K.R., Dilworth-Anderson, P., Klein, D. (Eds.) Sourcebook of Family Theory \& Research (pp.119-142). Thousand Oaks, CA: Sage Publications Inc.

Ehrle, G. M., Day, H. D. (1994). Adjustment and family functioning of grandmothers rearing their grandchildren. Contemporary Family Therapy, 16(1), 67-82.

Emick, M., Hayslip, B. (1999). Custodial grandparenting: Stresses, coping skills, and relationships with grandchildren. International Journal of Aging and Human Development, 48(1), 35-61.

Feldman, R. S. (2005). Development Across the Lifespan, $3^{\text {rd }}$ Edition. Upper Saddle River, NJ: Pearson.

Fuller-Thomson, E., Minkler, M. (2003). Housing issues and realities facing grandparent caregivers who are renters. The Gerontologist, 43(1), 92-98.

Fuller-Thomson, E., Minkler, M., \& Driver, D. (1997). A profile of grandparents raising grandchildren in the United States. The Gerontologist, 37, 406-411.

Geen, R. (2004). The evolution of kinship care policy and practice. In Children, families, and foster care (pp.131-149). The Future of Children, 14(1). 
Golby, B., Bretherton, I. (1999). Resilience in postdivorce mother-child relationships. In McCubbin, H., Thompson, E., Thompson, A., \& Futrell, J. (Eds) The Dynamics of Resilient Families (pp.237-269). Thousand Oaks, CA: Sage Publications.

Goodman, C. (2006). Grandmothers raising grandchildren: The vulnerability of advancing age. In Hayslip, B., Patrick, J. (Eds) Custodial Grandparenting: Individual, Cultural, and Ethnic Diversity (p.133-150). New York, NY: Springer.

Gilgun, J. F. (1999). Mapping resilience as process among adults with childhood adversities. In McCubbin, H., Thompson, E., Thompson, A., \& Futrell, J. (Eds) The Dynamics of Resilient Families (pp.41-70). Thousand Oaks, CA: Sage Publications.

Harrison, K., Richman, G., Vittimberga, G. (2000). Parental stress in grandparents versus parents raising children with behavior problems. Journal of Family Issues, 21(2), 262-270.

Hayslip, B. \& Kaminski, P. (2005). Grandparents raising their grandchildren. In Caputo, R. (Ed.) Challenges of Aging on U.S. Families: Policy and Practice Implications. Binghampton, NY: Haworth Publishing Company.

Hayslip, B., shore, R., Henderson, C., \& Lambert, P. (1998). Custodial grandparneting and the impact of grandchildren with problems on role satisfaction and role meaning. Journal of Gerontology: Social Services, 53B (3), S164-S173.

Hill, R. (1971). Families Under Stress. Westport, CT: Greenwood. (Original work published 1949)

Horton, T., Wallander, J. (2001). Hope and social support as resilience factors against psychological distress of mothers who care for children with chronic physical conditions. Rehabilitation Psychology, 46(4), 382-399.

Jendrek, M. (1993). Grandparents who parent their grandchildren: Circumstances and decisions. The Gerontologist, 34, 206-216.

Jendrek, M. (1993). Grandparents who parent their grandchildren: Effects on lifestyle. Journal of Marriage and the Family, 55(3), 609-621.

Kelley, S. J., Whitley, D., Sipe, T. A., \& Yorker, B. C. (2000). Psychological distress in grandmother kinship care providers: The role of resources, social support and physical health. Child Abuse \& Neglect, 24(3), 311-321. 
Kelley, S.J., Yorker, B.C., Whitley, D.M., \& Sipe, T.A. (2001). A multimodal intervention for grandparents raising grandchildren: Results of an exploratory study. Child Welfare League of America, 80(1), 27-50.

Keyes, C. L., Ryff, C. D. (1998). Generativity in adult lives: Social structural contours and quality of life consequences. In McAdams \& de St. Aubin (Eds.) Generativity and Adult Development: How and Why We Care for the Next Generation (pp.227263). Washington, D.C.: American Psychological Association.

Landry-Meyer, L., Gerard, J., Guzell, J. (2005). Caregiver stress among grandparents raising grandchildren: The functional role of social support. Marriage and Family Review, 37(1), 171-190.

Landry-Meyer, L., Newman, B. M. (2004). An exploration of the grandparent caregiver role. Journal of Family Issues, 25(8), 1005-1025.

Lavee, Y., McCubbin, H., Patterson, J. (1982). The double ABCX model of family stress and adaptation: An empirical test by analysis of structural equations with latent variables. Journal of Marriage and the Family, 47(4), 811-825.

Letiecq, B.L., Bailey, S.J., \& Conway, M.A. (in press). Depression among rural Native American and European American grandparents raising grandchildren. Journal of Family Issues.

Letiecq, B. L., Bailey, S. J., \& Porterfield, F. K. (2006). Intergenerational Ambivalence Among Grandparents Raising Grandchildren. Paper presented at the 68th National Council on Family Relations Annual Conference, Minneapolis, MN.

Lever, K., Wilson, J. (2005). Encore parenting: When grandparents fill the role of primary caregiver. The Family Journal: Counseling and Therapy for Couples and Families, 13(2), 167-171.

Lincoln, Y.S., \& Guba, E.G. (1985). Naturalistic inquiry. Beverly Hills, CA: Sage.

Lüscher, K. (2002). Intergenerational ambivalence: Further steps in theory and research. Journal of Marriage and Family, 64(3) 585-593.

Lüscher, K., \& Pillemer, K. (1998). Intergenerational ambivalence: A new approach to the study of parent-child relations in later life. Journal of Marriage and the Family, 60(2), 413-425. 
Mathmatica Policy Research, Inc. (2002, May). The Status of Families on Child-only TANF Cases. Retrieved October 5, 2006, from http://www.mathematicampr.com/publications/PDFs/wfnjchild.pdf

Mayer, M. (2002). Grandparents rearing grandchildren: Circumstances and interventions. School Psychology International, 23(4), 371-385.

McAdams, D., \& de St. Aubin, E. (1992). A theory of generativity and its assessment through self-report, behavioral acts, and narrative themes in autobiography. Journal of Personality and Social Psychology, 62(6), 1003-1015.

McAdams, D., de St. Aubin, E., \& Logan, R. (1993). Generativity among young, midlife, and older adults. Psychology and Aging, 8(2), 221-230.

McAdams, D., Hart, H., \& Maruda, S. (1998). The Anatomy of Generativity. In McAdams and de St. Aubin (Eds.), Generativity and Adult Development: How and Why We Care for the Next Generation (pp.7-43). Washington, D.C.: American Psychological Association.

McCubbin, H., \& McCubbin, M. (1988, July). Typologies of resilient families: Emerging roles of social class and ethnicity. Family Relations, 37, 247-254.

McCubbin, H., \& Patterson, J. (1983). Family transitions: Adaptation to stress. In McCubbin, H., \& Figley, C. (Eds.), Stress and the Family Volume I: Coping with Normative Transitions. New York, NY: Brunner/Mazel.

McGoldrick, M., Gerson, R., Shellengerger, S. (1999). Genograms: Assessment and Intervention 2nd Edition. W. W. Norton \& Company, New York, NY.

Minkler, M., Fuller-Thomson, E. (2000). Second time around parenting: Factors predictive of grandparents becoming caregivers for their grandchildren. International Journal of Aging and Human Development, 50(3), 185-200.

Minkler, M., Fuller-Thomson, E. (1999). The health of grandparents raising grandchildren: Results of a national study. American Journal of Public Health, 89(9), 1384-1389.

Minkler, M., Fuller-Thomson, E., Miller, D., \& Driver, D. (1997). Depression in grandparents raising grandchildren: Results of a national longitudinal study. Archives of Family Medicine, 6, 445-452.

Musil, C. (1998). Health, stress, coping, and social support in grandmother caregivers. Health Care for Women International, 19, 441-455. 
Musil, C., Ahmad, M. (2002). Health of grandmothers: A comparison by caregiver status. Journal of Aging and Health, 14(1), 96-121.

Musil, C., Warner, C., Zauszniewski, J., Jeanblanc, A., \& Kercher, K. (2006). Grandmothers, caregiving, and family functioning. Journal of Gerontology: Social Sciences, 61(2), S89-S98.

Nydegger, C. N. \& Mitteness, L. S. (1991). Fathers and their adult sons and daughters. In S. K. Pfeifer \& M. B. Sussman (Des.), Families: Intergenerational and generational connections (pp.259-266). Binghanton, NY: Haworth Press.

Patterson, J. M. (2002, May). Integrating family resilience and family stress theory. Journal of Marriage and Family, 64, 349-360.

Patton, M. Q. (2002). Qualitative Research \& Evaluation Methods, $3^{\text {rd }}$ Edition. Sage Publications: Thousand Oaks, CA.

Pinson-Milburn, N. M., Fabian, E. S., Schossberg, N. K., \& Pyle, M. (1996). Grandparents raising their grandchildren. Journal of Counseling \& Development, 74, 548-554.

Roe, K., Minkler, M., Saunders, F., \& Thompson, G. (1996). Health of grandmothers raising children of the crack cocaine epidemic. Medical Care, 34, 1074-1084.

Ross, M., Aday, L. (2006). Stress and coping in African American grandparents who are raising their grandchildren. Journal of Family Issues, 27(7), 912-932.

Sands, R., Goldberg-Glen, R. (2000). Factors associated with stress among grandparents raising their grandchildren. Family Relations, 49(1), 97-105.

Shih, M. (2004, January). Positive stigma: Examining resilience and empowerment in overcoming stigma. The Annals of the American Academy, 591(1), 175-185.

Smith, G., Savage-Stevens, S., Fabian, E. (2002). How caregiving grandparents view support groups for grandchildren in their care. Family Relations, 51, 274-281.

Stallings, M. C., Dunham, C. C., Gatz, M. Baker, L. A., \& Bengston, V. L. (1997). Relationships among life events and psychological well-being: More evidence for a two-factor theory of well-being. Journal of Applied Gerontology, 16(1), 104120. 
Strauss, A. L., Corbin, J. (1990). Basics of Qualitative Research: Grounded Theory Procedures and Techniques. Sage Publications. Newbury Park, CA.

Strom, R. D., Strom, S. K. (2000). Meeting the challenge of raising grandchildren. International Journal of Aging and Human Development, 51(3), 183-198.

Thompson, E. (1999). Resiliency in families with a member facing AIDS. In McCubbin, H., Thompson, E., Thompson, A., \& Futrell, J. (Eds) The Dynamics of Resilient Families (pp.135-164).Thousand Oaks, CA: Sage Publications

U. S. Census Bureau. (2000). Census 2000 data about grandparent-headed households Retrieved November 30, 2005 from http://www.aarp.org/families/grandparents/raising_grandchild/a2004-01-16census2000data.html

U. S. Census Bureau. (2003, October). Grandparents Living With Grandchildren: 2000. Census 2000 Brief. Retrieved November 16, 2006 from http://www.census.gov/prod/2003pubs/c2kbr-31.pdf

Waldrop, D. P., \& Weber, J. S. (2001). From grandparent to caregiver: The stress and satisfaction of raising grandchildren. Families in Society, 82, 461-472.

Walsh, F. (2002). A family resilience framework: Innovative practice applications. Family Relations, 51, 130-137.

Walsh, F. (1998). Strengthening Family Resilience. New York: Guilford.

Walsh, F., (1996). The concept of family resilience: Crisis and challenge. Family Process, 35, 261-281.

Whitley, D., Kelley, S., Sipe, T. (2001). Grandmothers raising grandchildren: Are they at increased risk of health problems? National Association of Social Workers, 26(2), 105-114. 
APPENDICES 


\section{APPENDIX A}

GRANDPARENTS RAISING GRANDCHILDREN: FAMILY LIFE HISTORIES INTERVIEW PROTOCOL 


\section{GRANDPARENTS RAISING GRANDCHILDREN: FAMILY LIFE HISTORIES}

\section{INTERVIEW PROTOCOL}

[After reviewing the consent form and obtaining signatures, begin the tape recorder.]

READ: Thank you for participating in this interview today. We are interested in learning more about your family and the transitions your family experienced that resulted in you becoming the primary caregiver of your grandchild(ren). As we move through this discussion, please feel free to opt out of answering any questions posed to you. If you need clarification about a question, please don't hesitate to ask. And remember that your participation is completely voluntary.

We have a lot of questions to ask you about your family. With this in mind, I may redirect you at times or ask you to come back to a story later in the interview. If you feel you still have more to say at the end of our time together today, we can schedule a second interview with you at your convenience.

Any questions? Let’s begin...

\section{GENOGRAM}

We are going to start our discussion by drawing a family genogram, which is a picture that represents your family structure-like a family tree. As we go through the genogram, we will ask you questions about the various members of your family and take notes so that we can remember who's who. We will be drawing four generations of your familyyour parents, your siblings/spouses, your children, and your grandchildren. We would like to start by learning more about the family you came from...

Let's begin with your parents. Tell us about your mother and father.

Are they still living?

If alive, where are they now?

If not, when did your mother/father die? What was the cause of death?

How many children did they have? (Your siblings)

Starting with the oldest sibling, tell me their names and about their marital history (cohabitation, marriages, separations, divorces, remarriages).

Do they have children?... 
[Continue until the family is completely drawn]

\section{Personal NarRative}

Now, we are interested in learning more about you and your personal history. Tell us about yourself... where you grew up, age, marriage history, numbers of children, education obtained, employment history, socioeconomic status (income status).

\section{YOUR CHILDREN}

Now, for each child, tell us his/her name, age, marital history, age at first birth, number of children, education, employment history, SES... and any other relevant pieces of information that will help us get to know your family better.

\section{TARget ChILD/GRANDCHILDREN UNDER CARE}

Now focus on the child for whom you are raising his/her child(ren). Tell us a little more about the events that lead up to you becoming a "second time around" parent.

\section{Potential Probes:}

- What were the first clues that there was a problem in your child's family?

- What was the relationship like before the "problems" emerged?

- How long did the problem last? Is it still a problem?

- Was there a low point in your child's life? How did you identify/come to understand this point?

- Has your child ever sought help? Did you as a family ever seek help?

- What is your relationship with your child like now?

- Do you have any rules or conditions for your child to meet before they can fully participate in your family again?

- If you aren’t in contact with your child, do you still think about him/her?

- What thoughts emerge? Feelings?

- Are you clear in your mind about what has happened? 
- What remains confusing about your relationship?

\section{GRANDCHILDREN}

Now tell us about your grandchildren.

- How are they doing?

- What has their adjustment process been like?

- How do you think your grandchild(ren) are coping with the situation?

- Do any of the grandchildren exhibit behavioral problems?

- Do any have special needs that require attention?

- How have you had to adapt with your grandchildren in terms of your parenting role?

\section{FAMILY SySTEM ADJUSTMENT}

Now think about your whole family...

- How has your family been affected by the shift in roles?

- How have your other children been affected? Your other grandchildren (not under your care)?

- How do you parent some of your grandchildren and grandparent others? How does that work?

- Genogram: Who’s in? Who’s out? Who’s connected?

o What are the patterns of relationships in your family?

- $\quad$ closeness

- distance

- cut-offs

- $\quad$ conflicts

-

\section{GrandPARENT Coping Strategies}

Individual: How did you prepare yourself for this new role of "second time around" parent?

How have you personally coped with this change in your life? How are you physically? Emotionally? 
Tell me about some of the feeling states that you have experienced/experience as you've transitioned in your role as GRG.

- $\quad$ Guilt?

- $\quad$ Fear?

- $\quad$ Loneliness?

- $\quad$ Hope?

- Joy?

- $\quad$ Pleasure?

- $\quad$ Acceptance?

- $\quad$ Other?

Relational: Have any relationships been affected by your transition to parenting your grandchildren?

- With your spouse?

- $\quad$ Other children?

- $\quad$ Friends?

- $\quad$ Co-Workers? Tell us about that...

Work: $\quad$ Tell me more about your work life...retirement planning...changes in career path?

Financial: What unexpected expenses have you incurred as a result of caring for your grandchild(ren)?
- $\quad$ Health care?
- $\quad$ Child care?
- $\quad$ Therapy?

What is the impact of any additional liabilities (e.g., new car payment, mortgage payment, increased credit debt) on your family?

Did the child come with any sources of income? (Does your child provide any support for his/her child(ren)? (Monetary? In-kind?)

Are you receiving TANF or Medicaid (CHIPS) or other assistance?

Are you concerned about your assets at the present time or have you experienced changes in your asset base since becoming the primary caregiver of your grandchild(ren)?

How do your other children feel about your current financial situation?

- $\quad$ Any support? 
Legal: $\quad$ What kind of legal assistance have you received?

$\begin{array}{ll}- & \text { Have you been involved with family court? } \\ - & \text { Custodial arrangements? } \\ - & \text { Visitation plan with adult child? }\end{array}$

Social Tell me about your social supports... who helps you?

Support: $\quad$ Who supports you in your role as GRG?

What professional supports have you received? Spiritual?

Support can sometimes be a drain on families too... are you experiencing any negative aspects of support?

Community: How do you feel you are treated/perceived generally when you share with others that you are a GRG?
$\bullet$
$\bullet$
$\bullet$
By the school system?
Legal system?
Others?

\section{RESOURCE NEEDS}

What has worked well for you as a GRG?

What do you need in order to function better in your daily life, if anything?

What programming/services might better meet your family’s needs?

\section{AdVICE TO NEW GRGS}

What advice would you give to new GRGs who are just starting out???

What have you learned from your experience that you would like to share with others? 


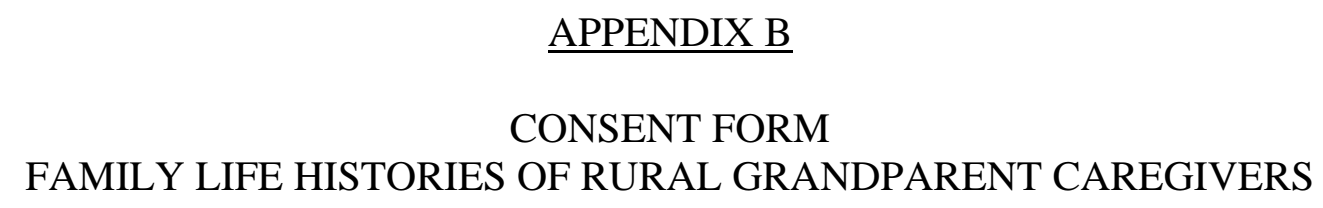


ID \#

\section{CONSENT FORM}

\section{FAMILY LIFE HISTORIES OF RURAL GRANDPARENT CAREGIVERS}

You are being asked to participate in a study that will examine the family life histories of grandparents who take on the primary role of raising their grandchildren. The study will focus on four related areas of grandparents' experiences including the health and well being of grandparents, the relationship between grandparents and their adult children, the relationship between grandparents and their grandchildren, and the coping strategies and resource needs of grandparent caregivers. Although you may not personally benefit from participating in this study, the research team hopes to better understand the strengths and needs of rural grandparents raising grandchildren in order to provide better services to grandparent caregivers in the future.

If you agree to participate in this study, you will be asked to participate in two in-person interviews, each lasting about 1 1/2 hours. Because we appreciate your time and value your contribution to this study, you will receive a $\$ 25$ stipend for the first interview and a $\$ 75$ stipend upon completion of the second interview. A third meeting time may be set up to verify that the information collected during the interviews is accurate and best captures your family story. There are no known risks involved in participating in this study, however, if any issues arise that are upsetting to you, we can make a referral to appropriate services as needed. Please note that you may stop the interview at any point without consequence to you. All information obtained in this study will be kept confidential. Only the research team will view the information gathered during the interviews and your name will not be used in conjunction with any reports produced by this effort.

If you have questions about the study, you may contact Dr. Bethany Letiecq at (406) 9947396 or by email at bletiecq@montana.edu, Dr. Sandy Bailey at (406) 994-6745 or by email at baileys@montana.edu, or you may contact Dr. Mark Quinn, Chair of the MSU Institutional Review Board for the Protection of Human Subjects, at (406) 994-5721.

AUTHORIZATION: I have read the above, am over 18 years of age, and understand the discomforts and/or inconvenience of this study. I, (participant name), agree to participate in this research. I understand that I may later refuse to participate, and that I may withdraw from the study at any time. I also understand that if I do not complete the study, I will not receive the 
whole benefit of the study. I have received a copy of this consent form for my own records.

\section{Print}

name:

\section{Address:}

(Street)

(City, State, Zip

Code)

Signature:

Date:

Social Security \#: [for payment purposes only]

Interviewer:

Date: 
$\underline{\text { APPENDIX C }}$

GRANDPARENTS RAISING GRANDCHILDREN: FAMILY LIFE HISTORIES PARTICIPANT BACKGROUND INFORMATION SHEET 


\title{
GRANDPARENTS RAISING GRANDCHILDREN: FAMILY LIFE HISTORIES
}

\author{
PARTICIPANT BACKGROUND INFORMATION SHEET
}

The following questions will help us gather general information about you. Your answers will be kept strictly confidential. Please be as honest as possible and make notations in the margins as needed for clarification.

1. What is your gender? $\square$ Male $\square$ Female

2. What is your age?

3. What is your relationship status?situation?:

Single, living alone years

Single, living with partner

Married

Widowed
What is your date of birth?

Number of years in current

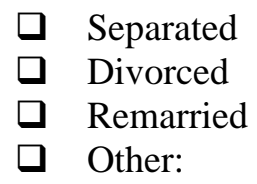

4. What is the highest level of education you have completed?

Some school: Number of years of primary schooling?

- High School Diploma/GED

Vocational or technical school beyond high school/Associate's Degree

Some College: Number of years of college?

College Degree (4-year)

$\square$ Some graduate school: Number of years of graduate

school?

Master's Degree

Doctorate or Professional Degree (e.g., medical or law degree)

5. What is your race or ethnic background?

口 White/Caucasian

$\square$ Native American

$\square$ African-American

specify:
ㄱon-White Hispanic or Latino

- Asian or Pacific Islander

Other, please

6. Which of the following best describes your working situation?

- Working for pay/employed

$\rightarrow$ If working for pay, what is your job title/occupation?

How many hours do you typically work per week?

$\square$ Retired

口 Temporarily unemployed

口 "Stay at home" parent/caregiver

$\square$ Student

O Other, please specify: 
7. What is your annual income?

$$
\begin{array}{ll}
\square & \$ 0-\$ 15,000 \\
\square & \$ 15,001-\$ 30,000 \\
\square & \$ 30,001-\$ 45,000 \\
\square & \$ 45,001-\$ 60,000 \\
\square & \$ 60,001-\$ 75,000 \\
\square & \$ 75,001-\$ 90,000 \\
\square & \text { over } \$ 90,000
\end{array}
$$

8. What is your total household income?

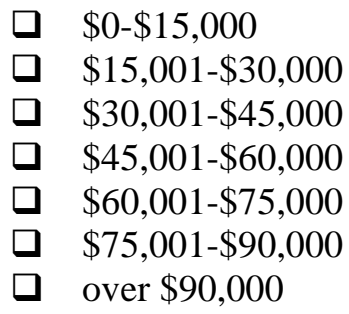

口 $\$ 0-\$ 15,000$

\$45,001-\$60,000

$\$ 75,001-\$ 90,000$

$\square$ over $\$ 90,000$

9. Do you receive government assistance? $\square$ Yes $\square$ No If yes, specify:

10. How long have you been providing primary care for your grandchild(ren)?: years

Thank you for providing us with this information. It will be used only to describe study participants in general terms when reporting results and disseminating study findings. Your name will not be associated with this form. 
$\underline{\text { APPENDIX D }}$

HUMAN SUBJECTS APPROVAL 


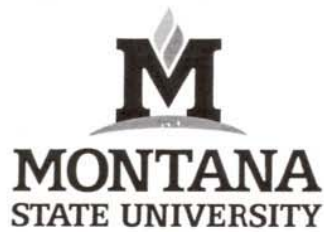 $\frac{\text { MONTANA }}{\text { STATE UNIVERSITY }}$}

MEMORANDUM

TO:

FROM:

Fonda Porterfield

Mark Quinn, Ph.D. Chair Mark
Institutional Review Board for the Prot

Ceumn

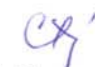

DATE:

April 2, 2007

SUBJECT:

\section{INSTITUTIONAL REVIEW BOARD For the Protection of Human Subjects FWA 00000165}

\author{
960 Technology Blvd. Room 127 \\ c/o Veterinary Molecular Biology \\ Montana State University \\ Bozeman, MT 59718 \\ Telephone: 406-994-6783 \\ FAX: 406-994-4303 \\ E-mail: cheryli@montana.edu
}

\author{
Chair: Mark Quinn \\ 406-994-5721 \\ mquinn@montana.edu \\ Administrator: \\ Cheryl Johnson \\ 406-994-6783 \\ cherylj@montana.edu
}

The above research, described in your submission of April 2, 2007, is exempt from the requirement of review by the Institutional Review Board in accordance with the Code of Federal Regulations, Part 46, section 101. The specific paragraph which applies to your research is:

(b)(1) Research conducted in established or commonly accepted educational settings, involving normal educational practices such as (i) research on regular and special education instructional strategies, or (ii) research on the effectiveness of or the comparison among instructional techniques, curricula, or classroom management methods.

X (b)(2) Research involving the use of educational tests (cognitive, diagnostic, aptitude, achievement), survey procedures, interview procedures or observation of public behavior, unless: (i) information obtained is recorded in such a manner that human subjects can be identified, directly or through identifiers linked to the subjects; and (ii) any disclosure of the human subjects' responses outside the research could reasonably place the subjects at risk of criminal or civil liability, or be damaging to the subjects' financial standing, employability, or reputation.

(b)(3) Research involving the use of educational tests (cognitive, diagnostic, aptitude, achievement), survey procedures, interview procedures, or observation of public behavior that is not exempt under paragraph (b)(2) of this section, if: (i) the human subjects are elected or appointed public officials or candidates for public office; or (ii) federal statute(s) without exception that the confidentiality of the personally identifiable information will be maintained throughout the research and thereafter.

(b)(4) Research involving the collection or study of existing data, documents, records, pathological specimens, or diagnostic specimens, if these sources are publicly available, or if the information is recorded by the investigator in such a manner that the subjects cannot be identified, directly or through identifiers linked to the subjects.

(b)(5) Research and demonstration projects, which are conducted by or subject to the approval of department or agency heads, and which are designed to study, evaluate, or otherwise examine: (i) public benefit or service programs; (ii) procedures for obtaining benefits or services under those programs; (iii) possible changes in or alternatives to those programs or procedures; or (iv) possible changes in methods or levels of payment for benefits or services under those programs.

(b)(6) Taste and food quality evaluation and consumer acceptance studies, (i) if wholesome foods without additives are consumed, or (ii) if a food is consumed that contains a food ingredient at or below the level and for a use found to be safe, or agricultural chemical or environmental contaminant at or below the level found to be safe, by the FDA, or approved by the EPA, or the Food Safety and Inspection Service of the USDA.

Although review by the Institutional Review Board is not required for the above research, the Committee will be glad to review it. If you wish a review and committee approval, please submit 3 copies of the usual application form and it will be processed by expedited review. 
APPENDIX E

HUMAN SUBJECTS EDUCATION CERTIFICATE 


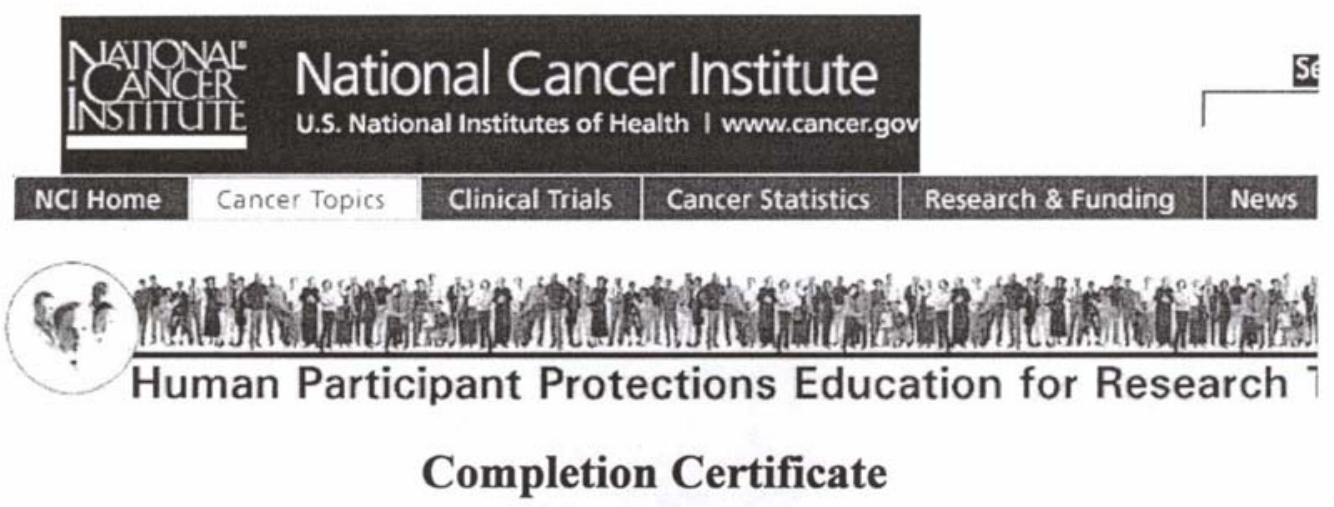

This is to certify that

\section{Fonda Porterfield}

has completed the Human Participants Protection Education for Research Teams online course, sponsored by the National Institutes of Health (NIH), on 01/24/2006.

This course included the following:

- key historical events and current issues that impact guidelines and legislation on human participant protection in research.

- ethical principles and guidelines that should assist in resolving the ethical issues inherent in the conduct of research with human participants.

- the use of key ethical principles and federal regulations to protect human participants at various stages in the research process.

- a description of guidelines for the protection of special populations in research.

- a definition of informed consent and components necessary for a valid consent.

- a description of the role of the IRB in the research process.

- the roles, responsibilities, and interactions of federal agencies, institutions, and researchers in conducting research with human participants.

National Institutes of Health http://www.nih.gov

Home | Contact Us | Policies | Accessibility | Site Help | Site Map

A Service of the National Cancer Institute

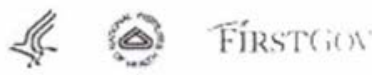

